NBER WORKING PAPER SERIES

\title{
THE WHITE/BLACK EDUCATIONAL GAP, STALLED PROGRESS, AND THE LONG TERM CONSEQUENCES OF THE EMERGENCE OF CRACK COCAINE MARKETS
}

\author{
William N. Evans \\ Craig Garthwaite \\ Timothy J. Moore \\ Working Paper 18437 \\ http://www.nber.org/papers/w18437 \\ NATIONAL BUREAU OF ECONOMIC RESEARCH \\ 1050 Massachusetts Avenue \\ Cambridge, MA 02138 \\ October 2012
}

The authors thank Jen Brown, Shawn Bushway, Meghan Busse, Jon Caulkins, Kerwin Charles, Dan Hungerman, Melissa Kearney, Jon Meer, Richard Murnane, Derek Neal, Emily Oster, Peter Reuter, Bruce Sacerdote, Bob Schwab, Doug Staiger, Jacob Vigdor, Tony Yezer and seminar participants at Cornell University, Kellogg School of Management, Syracuse University, University of Illinois at Urbana-Champaign, University of Maryland, University of Nevada-Las Vegas, University of Notre Dame, University of Texas at Austin, the IRP Summer Workshop at the University of Wisconsin, the Labour Econometrics Workshop at the University of Wollongong, and the NBER Summer Institute for their helpful comments. The views expressed herein are those of the authors and do not necessarily reflect the views of the National Bureau of Economic Research.

NBER working papers are circulated for discussion and comment purposes. They have not been peerreviewed or been subject to the review by the NBER Board of Directors that accompanies official NBER publications.

(C) 2012 by William N. Evans, Craig Garthwaite, and Timothy J. Moore. All rights reserved. Short sections of text, not to exceed two paragraphs, may be quoted without explicit permission provided that full credit, including $\odot$ notice, is given to the source. 
The White/Black Educational Gap, Stalled Progress, and the Long Term Consequences of the Emergence of Crack Cocaine Markets

William N. Evans, Craig Garthwaite, and Timothy J. Moore

NBER Working Paper No. 18437

October 2012

JEL No. I0,I2,I21,I28,J0,J01,J1

\title{
ABSTRACT
}

We propose the rise of crack cocaine markets as an explanation for the end to the convergence in black-white educational outcomes beginning in the mid-1980s. After constructing a measure to date the arrival of crack markets in cities and states, we show large increases in murder and incarceration rates after these dates. Black high school graduation rates also decline, and we estimate that crack markets accounts for between 40 and 73 percent of the fall in black male high school graduation rates. We argue that the primary mechanism is reduced educational investments in response to decreased returns to schooling.

\author{
William N. Evans \\ Timothy J. Moore \\ Keough-Hesburgh Professor of Economics \\ Department of Economics \\ Department of Economics and Econometrics \\ 447 Flanner Hall \\ George Washington University \\ University of Notre Dame \\ 340 Monroe Hall \\ 2115 G Street, NW \\ Notre Dame, IN 46556 \\ and NBER \\ wevans1@nd.edu \\ Washington, DC 20052 \\ tim_moore@gwu.edu \\ Craig Garthwaite \\ Department of Management and Strategy \\ Kellogg School of Management \\ Northwestern University \\ 2001 Sheridan Road \\ Evanston, IL 60208 \\ and NBER \\ c-garthwaite@kellogg.northwestern.edu
}




\section{Introduction}

Historically, there are persistent differences between the high school graduation rates and standardized test scores of white and black students. ${ }^{1}$ These differences narrowed between the mid1960s and the late-1980s as the educational outcomes of black students improved dramatically. Then, for reasons that previous academic and policy researchers have been unable to explain, this progress stopped. We argue that the introduction and spread of crack cocaine markets in the 1980s and 1990s explains a large fraction of the "stalled progress" in black educational outcomes.

The trends for high school graduation rates are shown in Figure 1. This is produced using data from the pooled 2005-2009 American Community Survey (ACS) (Ruggles et al., 2010). ${ }^{2}$ We place U.S. born, non-Hispanic white and black respondents into cohorts based on the year they turned age 18. Figure 1a contains the race-specific high school graduation rates for cohorts turning 18 between 1967 and 2004, while Figure 1b shows the white-black difference in these rates. Several facts are of note. First, the gap in graduation rates halved between 1967 and 1986, falling from 9.2 to 4.4 percentage points. Second, almost all of the convergence is due to rising black achievement— the graduation rates of whites changed little over this period. Third, the convergence ends in 1986 and white-black graduation rates diverge until 2003 when the gap is 7.8 percentage points. Fourth, as with the convergence, the divergence is almost entirely driven by black graduation rates, which declined by 4.4 percentage points between 1986 and 2004. This wiped out much of the previous progress: the black cohort that turned 18 in 2004 had a graduation rate similar to the 1972 cohort.

The decline in graduation rates for blacks is primarily driven by the outcomes for males. We

\footnotetext{
${ }^{1}$ For data on the test score gap, see Jencks and Phillips (1998), Neal (2006) and Magnuson and Waldfogel (2008). For data on the high school graduation gap, see Rivkin (1995), Heckman and LaFontaine (2010).

${ }^{2}$ These graduation rates are higher than estimates one would obtain from sources such as the October School Enrollment Supplement to the Current Population Survey (CPS) because the ACS does not distinguish between regular high school graduates and those obtaining a degree via the GED. Since individuals acquire the GED over time, older cohorts have had more time to acquire the degree. Neal (2006) finds the GED narrows the white-black gap in high school graduation but does not change the trends, while Heckman and Lafontaine (2010) find progress in narrowing black-white differences is overstated by the inclusion of the GED.
} 
report the high school graduation rates in the ACS by race and sex in Figure 1c and the sex-specific white-black difference in these rates in Figure 1d. Between the 1967 and 1986 cohorts, high school graduation rates increased by 4.7 and 6.7 percentage points for black females and males, respectively. Between 1986 and 2004, graduation rates for black males fell by 5.7 percentage points while, over the same period, the rate for black females fell by one percentage point.

A number of hypotheses have been put forward to explain the convergence in educational outcomes between the 1960s and the mid-1980s, including improved parental education (Armor, 1992), reduced segregation (Jaynes and Williams, 1989), increases in school spending (Boozer et al., 1992), and better access to health care (Chay et al., 2009). Less attention has been paid to the end of this convergence. Neal (2006) argues that pathways such as changes in the race-specific educationwage relationship, income shocks to black families, school factors, and cultural changes do not explain the trends and concludes: "It is not clear why the process of black-white skill convergence appeared to stop around 1990” (p. 570). The chapters in Magnuson and Waldfogel (2008) examine factors such as changing family income, rising income inequality, relative changes in parental education, changes in school segregation, and changes in teacher quality as possible explanations for these trends. They conclude that while these factors may account for a slowing convergence, none explain the stalled progress. ${ }^{3}$

A potential explanation is the widespread emergence of crack cocaine markets. Crack cocaine was an innovation that cut the price of cocaine and dramatically expanded the market size and profits from drug dealing. The drug first appeared in Miami, New York, and Los Angeles around 1982, and then spread to cities and towns across the nation over the next decade. Intense competition among suppliers produced unprecedented violence and incarceration. We hypothesize that decreased life

\footnotetext{
${ }^{3}$ In the final chapter, Ferguson (2008, p. 321) notes that “....researchers, parents, activists, and policy makers still seek to understand why progress stalled in 1990."
} 
expectancy, increased likelihood of imprisonment, and new source of informal earnings lowered individuals' expected returns to human capital and subsequent investment in education. Neal (2006) and Fryer et al. (forthcoming) have previously suggested a connection between crack cocaine markets and educational progress, although neither examines whether there is a relationship between them.

The changes in violence and incarceration were large enough to have substantially altered young black males' expectations about their future. Consider how their risk of dying changed in the 1980s and 1990s. Suppose that 15 year olds estimate their chance of dying by age 30 by examining the contemporaneous, age-specific mortality rates of older individuals living in the same city and who share the same sex and race. For example, a 15 year old black male in the District of Columbia (DC) uses the annual death rates of older black males in DC to judges his cumulative risk. ${ }^{4}$ Figure 2 shows this calculation from 1980 to 2000 for black males in DC, Dallas, Saint Louis, and New Orleans. ${ }^{5}$

In 1980, a 15 year old black male in DC would have estimated his risk of dying before age 30 to be four percent. This increases sharply after 1985, and by 1993 a 15 year old black male's risk of death by age 30 is 12 percent. It declines to six percent by 2000. In Dallas, New Orleans and St. Louis, cities in different parts of the U.S., 15 year old black males' risk of death by age 30 increased by 3.5-8 percentage points from the mid-1980s to the early-to-mid 1990s. In contrast, the changes in perceived mortality risks for white males, white females, and black females over this period were generally less than one percentage point in these cities. These changes in mortality risks are broadly similar to those resulting from the AIDS epidemic in Africa (Chicoine, 2012). Furthermore, incarceration risks also increased sharply over this period. Bonczar (2003) estimates that black males' lifetime chance of going to prison changed from 13 to 31 percent between 1979 and 1997.

\footnotetext{
${ }^{4}$ The expected mortality rate by age 30 is the sum the contemporaneous mortality rates of 15 year olds, 16 year olds (conditional on living to 16), 17 year olds (conditional on living to 17), and so on, up to and including those aged 29.

${ }^{5}$ The mortality data come from the National Center for Health Statistics' Multiple Cause of Death data, while population data is from the Census. These sources are described later in the paper.
} 
Ethnographic accounts and surveys indicate that school-age children were aware of these high risks. Children frequently reported witnessing shootings and murders. ${ }^{6}$ Many also carried guns. A nationally-representative survey of 12,000 students found that four percent of respondents and 21 percent of black male respondents reported carrying a gun at least once in the previous 30 days (U.S. Department of Health and Human Services, 1991). Anderson (1994, p. 94) found inner-city youth were "uncertain about how long they are going to live and believe they could die violently at any time. They accept this fate." Such views may alter behavior; studies in the adolescent health literature find that expectations of premature death among school age children are correlated with lower adult socioeconomic status and lower levels of education (Nguyen et al., 2012), worse adult health outcomes (Borowsky et al., 2009), higher adolescent violence (Stoddard et al, 2011) and selfdestructive behavior (McDade et al. 2011).

We exploit city- and state-level variation in the introduction and severity of crack cocaine markets to examine their impact on the white-black education gap. Using cocaine-related deaths recorded in the Multiple Cause of Death data, which were rare before the introduction of crack cocaine, we date the arrival of crack markets in 57 cities and 41 states. Our dates correspond well with other published estimates. We also show these dates appear to have more to do with geography and population size than local socioeconomic indicators, suggesting that crack markets did not systematically emerge in response to changing educational or other socioeconomic characteristics.

We then show that the arrival of crack cocaine is strongly predictive of increases in young black males' murder rates and of decreases in their high school graduation rates. The nature of this latter relationship is shown in Figure 3a, where we report average graduation rates for U.S. born

\footnotetext{
${ }^{6}$ For example, Schubiner, Scott, and Tzelepis (1993) found that, among 14-23 year old black youths in Detroit, 42 percent had witnessed a shooting and 22 percent had seen someone killed. Other researchers report similar statistics among inner-city youth in Baltimore (Gladstein et al., 1992) and New Orleans (Osofsky et al., 1993).
} 
black and white non-Hispanic males based on the year crack markets arrived in their MSA. The zero on the horizontal axis is the year crack cocaine arrived. ${ }^{7}$ Differences in male graduation rates narrowed before crack cocaine arrived, in line with the literature on convergence. The 18-year-old black male graduation rate starts to fall two years after crack markets emerge. In Figure 3b, we see a similar pre-crack increase in graduation rates for non-Hispanic black females in the 57 MSAs, but a less pronounced drop following the arrival of crack markets.

Similar patterns are observed in a sample of comparably-defined respondents who live in the 41 states with the largest black populations, as shown in Figures 3c and 3d. One contribution of this paper is to document large changes in youth murder rates outside of major cities, which helps to explain a widespread connection between crack markets and educational outcomes. Major cities have often been the focus of reporting and research into crack markets, and this has sometimes created an impression that crack cocaine could not explain stalled progress in other locations (Neal, 2006). In reality, crack markets were established in many small cities and towns. ${ }^{8}$

We develop two measures of the intensity of crack markets. The first is the murder rate of young adults aged 20-24 that a sex and race specific birth cohort experienced when they were aged 16 to 18 years. We find that a higher murder rate lowers the probability of graduating high school for males but not females. These relationships are similar after adding time-varying and race-specific variables designed to account for general economic events. The second measure of crack market intensity is the annual race-specific fraction of 20-24 year old males entering prison in the year each cohort turned 18. This is calculated using state-level data from the Bureau of Justice Statistics' National Corrections Reporting Program. A higher prison entry rate decreases the high school

\footnotetext{
${ }^{7}$ This data is taken from the IPUMS version of the 2000 Census five percent Public Use Micro Samples (Ruggles et al., 2010). The sample is residents of the 57 largest MSA used in Table 3. Cohorts are based on when they turn 18.

${ }^{8}$ Massing (1989) provides specific examples of the presence of crack houses and crack selling in numerous small towns, including Newburgh (1990 population of 26,000) and Kingston $(24,000)$ in New York State; Martinsburg $(13,000)$ and Charles Town $(3,000)$ in West Virginia; and Chambersburg $(15,000)$ in Pennsylvania.
} 
graduation probability of males. Murder and incarceration rates are independently predictive of changes in males' high school graduation in a regression containing both measures. Depending on assumptions about the continued progress of black males, the combined effect accounts for 40 to 73 percent of their change in graduation rates between the early 1980s and the middle of the 1990s.

In the late 1990s and early 2000s, the pace of the decline in black male high school graduation rates slowed but did not return to the pre-crack trend of white-black convergence. While murder rates declined during this period, our estimates suggest that this may have been largely offset by the continued increase in incarceration rates. There is also evidence for the intergenerational and cultural transmission of education (Bjorklund et al., 2006; Sacerdote, 2007), so it is not clear we should see a return to the pre-crack convergence even after murder rates began to decline.

While there are a number of pathways through which crack markets could impact educational outcomes, we argue that changing the returns to education is the primary channel. Mechanisms affecting families, schools, or neighborhoods, like parental crack use, disruption in schools, or the disintegration of family life, do not explain the larger decline in high school graduation rates of black males compared to black females. We also examine the long-term trends in standardized test scores at ages nine, 13 and 17 years. The score gaps of nine year olds continued to narrow, in contrast to widening gaps for 13 and 17 year olds. Finally, it is unlikely that crack cocaine use among teens can explain these as use rates by school-age children were low in absolute terms and similar across races.

These estimates also provide insights into whether factors that limit the benefits of education lower human capital investment. Previous tests of this hypothesis have exploited shocks to the length of life that should be unrelated to other factors affecting human capital investment. Jayachandran and Lleras-Muney (2009) find increased female education in post-World War II Sri Lanka following a sharp drop in maternal mortality. Fortson (2011) shows that areas of sub-Saharan Africa with the 
largest increases in mortality from the HIV epidemic have the largest decline in schooling. Finally, Oster et al. (2012) find that individuals who learn they possess the genetic mutation responsible for the fatal Huntington's disease have lower educational attainment and participate in less job training.

Crack markets had three primary impacts on young black males: an increased probability of being murdered, an increased risk of incarceration, and a potential source of income. Each limits the benefits of education. Our results show that crack markets explain most of the stalled progress in black male educational outcomes, which provides further evidence that individuals invest in human capital in a manner consistent with the models of Becker (1964) and Ben-Porath (1967).

\section{Crack Cocaine Markets in the United States}

Crack cocaine was introduced from the Caribbean around 1981, first in Miami and soon after in Los Angeles and New York. The drug is made by cooking powder cocaine with baking soda, and is then broken up and smoked once it cools and hardens. Crack was easier to produce than other types of smokeable cocaine and produced a more intense high than intra-nasally ingested powder cocaine (Agar, 2003). Crack cocaine users report that smoking it yields a high lasting 20 minutes, followed by a sharp crash and an intense drive to get high again (Fagan and Chin, 1989). The drug proved to be popular with existing and new users of cocaine, who could buy a "hit" of crack for as little as $\$ 5$ (Witkin, 1991). Selling it could be extremely profitable, with police estimating that a $\$ 5,000$ investment in powder cocaine could yield $\$ 125,000$ in crack sales (GAO, 1989).

The simple technology and small quantities of cocaine required to make crack meant it could be locally cooked and distributed by small and decentralized organizations. ${ }^{9}$ This was unlike existing

\footnotetext{
${ }^{9}$ According to Massing (1989): “A typical crack organization would have no more than seven or eight people - a street seller or two, a steerer to direct customers, a guard to protect the merchandise, a police lookout, a weigher (known as a "scale boy"), a manager and a 'Mr. Big' to count the profits."
} 
drug markets that required large amounts of capital or expertise, and were primarily controlled by long established organized criminal enterprises. The combination of low entry barriers and high profit potential led to large amounts of entry and fierce competition (Fagan and Chin, 1989). For example, qualitative data from 1,500 crack cocaine sellers in New York suggest that the majority of low-level dealers were entrepreneurs who owned the drugs (Caulkins et al., 1999).

The potential for violence resulted from both the type of customers buying crack and the sales location. Crack cocaine was affordable to a low-income population priced out of the powder cocaine market. Buyers would often purchase one "hit" at a time, which generated many transactions and more opportunities for violence than other drug markets (Blumstein, 1995). The retail market initially operated though "crack houses," which also offered a place to use the drug. However, as the popularity of crack increased, dealers moved to street corners where they used violence to establish and protect their own sales area (Fagan and Chin, 1989; Reuter et al., 1990). This violence was primarily perpetrated using firearms. A diffusion of guns for self-defense further increased violence in areas with crack markets resulting in large increases in the homicide rates of young black males that extended beyond crack cocaine users and distributors (Blumstein, 1995).

\section{a. The Spread of Crack Cocaine Markets}

The availability of crack cocaine spread across the United States over the course of the 1980s and early-1990s. The three cities where the drug first appeared - Los Angeles, Miami and New York City - remained the key distribution points for cocaine over this time, and strongly influenced where crack markets later developed. The emergence crack markets in a city was primarily driven by the decisions of national trafficking groups such as the Jamaican "posses" based in New York and Miami, and "The Bloods" and "The Crips" African-American street gangs of Los Angeles (Witkin, 1991). As competition in these three cities became intense, enterprising groups moved to new areas 
where they could sell crack at higher prices (Massing, 1989; Witkin, 1991). Traffickers initially

looked for large cities that were easily accessible from their distribution hubs. Crack markets were also established in many nearby smaller cities. The arrival of these national organizations often led to violent confrontations with the local entrepreneurs. These conflicts were exacerbated when multiple national organizations simultaneously entered an area.

\section{b. Identifying the Arrival of Crack Cocaine}

In order to estimate long-run impacts of the crack epidemic on educational outcomes, we require a measure of when crack markets begin in cities and states. Despite numerous ethnographic accounts of crack markets, there is a lack of systematic measures of the arrival of crack across a large number of cities and states. ${ }^{10}$ The difficulties associated with measuring illicit drug markets are compounded by surveys and administrative data not distinguishing crack from powder cocaine.

Our approach is to use cocaine-related deaths to estimate when crack arrived in specific locations. Few deaths in the United States had a cocaine-related cause prior to the introduction of crack, with reported cocaine-related deaths numbering 13 in 1979, nine in 1980, and eight in 1981. ${ }^{11}$ The number of cocaine-related deaths increased dramatically thereafter, with 67 deaths in 1985, 523 in $1989,1,075$ in 1994, and 1,497 in 1998. Given that the consumption of powder cocaine did not change substantially over this period, it seems reasonable to attribute this increase to the use of crack

\footnotetext{
${ }^{10}$ Existing measures of when crack markets emerged, like those in Grogger and Willis (2000), are for fewer than 30 cities. Other measures, such as Fryer et al. (forthcoming), are indices that do not pinpoint when crack arrives.

${ }^{11}$ These tabulations are from the public-use versions of the National Center for Health Statistics' (NCHS) Multiple Cause of Death (MCOD) data files. They contain a unique record of each death in the United States, including information about each decedent's age, race, gender, place of residence, and cause of death. The public-use files are provided by the National Bureau of Economic Research: http://www.nber.org/data/vital-statistics-mortality-data-multiple-cause-of-death.html. Deaths in the United States between 1979 and 1998 are coded according to the $9^{\text {th }}$ Revision of the International Classification of Diseases system (ICD-9) system. The relevant ICD-9 codes are 304.2 (Cocaine dependence) and 305.6 (Cocaine abuse).
} 
cocaine (Boggess and Bound, 1997). ${ }^{12}$ While the cocaine-mortality relationship is not direct enough to use death records to measure the intensity of crack cocaine use (Derlet and Albertson, 1989), multiple cocaine-related deaths in a location is a consistent and widely available measure that likely indicates the presence of crack cocaine. We create consistent mortality counts from 1980 to 1998 for every Metropolitan Statistical Areas (MSA) with a 1980 population over 800,000 . We then define the arrival of crack as the first of two consecutive years where cocaine-related deaths are reported.

These MSAs and the estimated years that crack cocaine arrived are listed in Table 1. The crack arrival years span 1982 to 1994 . The three MSAs with the earliest arrival of crack are Los Angeles/Long Beach, Miami and New York, which matches reports on where crack cocaine first appeared. While it is possible this reflects powder cocaine deaths, none of these MSAs would have met the same test of consecutive cocaine-related deaths in 1980 or $1981 .{ }^{13}$ Our dates are generally within a year of the earliest dates given in newspaper reports and ethnographies for larger cities. ${ }^{14}$

These dates are similar to the ones used by Grogger and Willis (2000), who surveyed police chiefs in 1991 about when they first became aware of the existence of crack. They received responses for 25 cities. In 22 cities they also used data from the Drug Abuse Warning Network (DAWN), a surveillance system that monitors drug-related visits to hospital emergency departments, to identify when there is an increase in reports of smoking cocaine. The correlation coefficient between our measure and the police survey dates is 0.43 , and between our measure and the DAWN measure is 0.37. These correlations are higher than the correlation across their two sets of dates, which is 0.32 .

A similar approach is taken for dating the arrival of crack cocaine in states and the District of

\footnotetext{
${ }^{12}$ Data from the 1982 National Household Survey on Drug Abuse (NHSDA) indicates that the past-year cocaine use rate was 6.4 percent, which was most likely all powder cocaine use. The same survey for 1995 indicates a one-year use rate of 1.7 percent which includes use of powder and crack cocaine. The one-year crack use rate from the 1995 survey was 0.5 percent.

${ }^{13}$ Only the Nassua/Suffolk MSA (NY) consistently reports cocaine-related deaths prior to 1981; it is omitted from the sample. See the online appendix for more details.

${ }^{14}$ More details about our approach, alternate measures, and a comparison to other sources are provided in an appendix.
} 
Columbia. The crack arrival dates for 41 states, again using a measure based on two consecutive years, are presented in Table $2 .{ }^{15}$ The earliest dates are 1981 for California and 1982 for Florida and New York. Overall, the state-level dates are more compressed, with all 41 states having crack cocaine by 1988. The dates are roughly in accord with other evidence of the arrival of crack markets.

\section{c. Factors Affecting the Spread of Crack Markets}

We noted above that some observers have emphasized the importance of proximity to the major cocaine distribution hubs of New York, Miami and Los Angeles in the development of crack cocaine markets (Massing, 1989). Witkin (1991, p. 52) said, "America was caught in a pincer movement; Los Angeles street gangs moved east and Jamaican posses move west from the East Coast, and between them .... they had introduced much of the rest of the country to crack." If true, the spread of crack cocaine should be related to proximity to the three hubs and less influenced by existing social and economic trends that may separately influence educational outcomes.

Tabulating the minimum driving distance to New York, Miami and Los Angeles by the years that crack arrives suggests there is some relationship. For cities estimated to get crack markets in 1983 and 1984, the median minimum distance from New York, Miami, and Los Angeles is 340 miles, compared to 424 miles for cities with arrival dates of 1985 and 1986, 559 miles for cities with arrival dates of 1987 and 1988, and 638 miles for cities with arrival dates after 1988.

We can also examine the role of distance together with other factors using a Weibull duration model, with the dependent variable equal to the number of years after 1980 that crack cocaine is estimated to arrive. In addition to the minimum distance to New York, Miami or Los Angeles, we include the natural log of population, percentage white, percentage black, percentage of blacks in

\footnotetext{
${ }^{15}$ In the three most populous states of California, New York and Texas, the measure used is more than two deaths two years in a row Ten states with small black populations are omitted because they do not have enough observations to analyze education outcomes.
} 
poverty, percentage of blacks who are unemployed, percentage of blacks who are high school

dropouts, percentage of blacks who are high school graduates, and the percentage of blacks who have some college education. We estimate an initial model using values in the 1980 Census, and then a second model using the changes in these variables between the 1970 and 1980 Censuses. ${ }^{16}$

The results of these models are presented in Table 3. Hazard rates and 95 percent confidence intervals for the models are presented in Column (1), which shows that only the log 1980 population and the minimum distance from New York, Miami, and Los Angeles are predictive of the length of time it takes for crack markets to emerge in a city. Larger cities are more likely to get crack markets earlier, while cities farther from the three distribution hubs were likely to get crack later. The model based on changes in covariates between 1970 and 1980, shown in Column (2), displays a similar pattern except the estimated coefficient on the minimum distance variable is only statistically significant at a p-value of $0.10 .^{17}$ These results suggest the spread of crack markets was not strongly related to differences in the economic characteristics of MSAs level; further support for this comes from examining the relationship between murder rate changes and economic characteristics.

\section{The Introduction of Crack Markets and the Murder and Incarceration of Youths}

In this section, we provide more details about the rise in youth murder and incarceration rates discussed above and consider the connection to crack markets. While we focus on these two

\footnotetext{
${ }^{16}$ The sample contains the 50 MSAs identified in both our crack arrival data and the 1970 and 1980 five percent PUMS.

${ }^{17}$ It is possible that the timing of the crack epidemic was unrelated to key economic variables but the differential severity across cities was driven by socioeconomic characteristics. To further explore this question, we estimated an OLS model with the same explanatory variables as the survival model and a dependent variable equal to the city-specific difference in the minimum murder rate in the $1980 \mathrm{~s}$ and the maximum murder rate in the 1990s for black males aged 20 to 24 for a sample containing the 104 MSAs jointly identified in the 1970 PUMS, 1980 PUMS, and the MCOD data. For explanatory variables defined as either levels or pre-existing trends from 1970 to 1980 , the change in murder rate is negatively correlated to population and positively correlated to the minimum distance at a p-value of 0.05 . No other variables are statistically significant at this p-value. For the levels specification, a one standard deviation change in the minimum distance variable was associated with an increased in the murder rate of 29 per 100,000. The negative estimate for log 1980 population corresponds to the graphical evidence in Figure 5d showing that smaller cities had the largest increases in their murder rate during this time period. This does not reflect a pre-existing relationship between murder rates and distance to LA, NYC, and Miami. For a specification with explanatory variables in levels and a dependent variable equal to change in the murder rate from 1973 to 1980 the estimate (standard error) for the coefficient on the minimum distance variable was $0.0013(0.0340)$.
} 
outcomes because they are well measured for different demographic groups and across many

locations, there is evidence that related outcomes like assaults and gunshot wounds also increased (Boggess and Bound, 1997; Fryer et al., forthcoming).

\section{a. The Rapid Rise in Murder Rates in the 1980s}

The aggregate annual murder rate was reasonably stable between 1980 and 1995, at between eight to ten deaths per 100,000 residents, before declining to six deaths per 100,000 by $2000 .^{18}$ However, this masks enormous differences across age groups. Figure 4a shows the murder rates for four age groups: less than 15 years; $15-24$ years; $25-39$ years; and 40 years and older. What is most striking is the large increase among 15-24 year olds, where the rate increases by 94 percent from 1985 to 1993 . There is a 10 percent increase in the homicide rate among 25-39 year olds over the same period, while the rates for those aged less than 15 years are small and reasonably flat. The homicide rate for those aged over 40 declines throughout the period. The homicide rate among 15-24 year olds is lower than 25-39 year olds at the beginning of the period, but by 1993 it is 50 percent higher than the 25-39 age group and several times higher than the rates for other age groups.

To understand which subgroups of 15-24 year olds account for these changes, Figure $4 \mathrm{~b}$ shows the homicide rates of 15-24 year old black males, black females, white females and white females. Note that because the black male homicide rate is many times higher than the rates for the other groups, it is measured on the right vertical axis while the other three groups in reference to the left vertical axis. Starting in the middle of the 1980s, there is a large increase in the homicide rate for black males aged 15-24 years. Their rate increased from 66 in 1985 to 166 in 1993, an increase of

\footnotetext{
${ }^{18}$ Homicides are taken from the public-use versions of the National Center for Health Statistics' Multiple Cause of Death (MCOD) data files. These files contain a unique record of each death in the United States, including information about each decedent's age, race, gender, place of residence, and cause of death. The public-use files are provided by the National Bureau of Economic Research: http://www.nber.org/data/vital-statistics-mortality-data-multiple-cause-of-death.html. Population data is Census data that is compiled by Cancer SEER.
} 
150 percent over an eight year period. Over the same period, the homicide rates of white males and black females increased from 11 to 17 and from 14 to 22, respectively. The homicide rates for all three demographic groups decline between 1993 and 2000 by 42 to 51 percent. The homicide rate for white females is the lowest of the four groups, and is flat or declining throughout the sample period.

We can also look at how these changes differed by location. Figure $4 \mathrm{c}$ shows the relative change since 1980 in the murder rate of black males aged 15-24 years for different city sizes. The largest increase was in cities with 250,000 - 500,000 residents, followed by cities with 100,000 250,000 residents. The smallest relative increase in murders was for cities with greater than 500,000 residents. This indicates that the increase in murder rates occurred outside of major cities. This fact is reinforced by noting that of the 100 MSAs with the largest black population, the five cities with the largest absolute change in the murder rate between the 1980s and 1990s of black males aged 15-24 years were: Youngstown, OH; New Orleans, LA; Gary, IN; Shreveport, LA; and Chattanooga, TN. Each city experienced an absolute increase in their murder rate of over 300 per 100,000 residents (or 0.3 percent). Their locations are also consistent with suggestions that competition in the middle of the country led to the worst crack-related violence (Massing, 1989; Witkin, 1991).

\section{b. Increased Incarceration}

The number of federal and state prisoners more than doubled from 1980 to 1996, driven by a nine-fold increase in incarceration numbers for drug offenses (Blumstein and Beck, 1999). To examine state-based differences in the probability of incarceration by age and race, we construct a prison intake measure from restricted use data provided by the Bureau of Justice Statistics National Corrections Reporting Program (NCRP) from 1983 to 1999. The NCRP tracks the entry and exit from prisons, and includes basic demographic information and where the sentence was imposed. The 
NCRP data do not report previous incarcerations for those entering prison, so we are not able to identify first-time incarcerations. We instead calculate the percentage of each demographic group that enters prison in a particular year. There is inconsistent participation in the NCRP by states over time. Although 36 states participate in an average year, only 17 states provided intake data for each year from 1983 to $1999 .{ }^{19}$ The lack of data prior to 1983 and the small number of states reporting in the mid-1980s means that there is little intake data prior to the arrival of crack markets.

Despite these limitations, the NCRP data provide insights into the general increase in imprisonment in the 1980s and the differences in this change by racial groups across states and over time. Panel D of Figure 4 contains the prison intake rate for males aged 20 to 24 from 1983 to 1999 for the 17 states reporting data in each year. In 1983, the fraction of black and white males entering prison was 0.86 percent and 0.12 percent, respectively. Over the next 16 years, the prison intake rate for black males increased by 3.3 percentage points, compared to a 0.3 percentage point increase for white males. By 1999, the original 0.7 percentage point racial gap in rates grew to 3.6 percentage points. It is important to note that none of these figures include jails, which generally hold around 40 percent as many people as state and federal prisons (Caulkins and Chandler, 2006).

There was substantial variation across states in terms of these changes. In 1984 the state-level prison intake rates for black males aged 20 to 24 ranged from 0 to 1.4 percent. A decade later, this range was 0.3 to 6.9 percent. This state-based variation likely results from factors such as state drug laws, sentencing policies, and the level of activity and violence in the crack markets.

\section{c. The Arrival of Crack Cocaine and Youth Homicide}

In this section we examine how murder rates changed after the arrival of crack. Figure 5

\footnotetext{
${ }^{19}$ The states participating in each year are AL, CA, CO, IL, KY, MD, MI, MN, MS, MO, NE, NH, ND, OR, TN, WV, and WI. An additional 6 states (NJ, NY, NC, NC, OH, SC, and WA) are included in 16 of the 17 years.
} 
shows the murder rates of different age and demographic groups for the eight years before and after the arrival of crack in the 57 MSAs for which we have arrival dates. ${ }^{20}$ Panel A shows the rates for black males aged 15-24 years, 25-39 years, and 40 years and older. The 15-24 year old murder rate is flat prior to the arrival of crack, then increases after the arrival of crack markets and doubles by six years after crack arrival. Black males aged of 25 to 39 experienced a 12 percent increase after crack arrival, while there is no change in the trend for black males aged 40 and older.

Panel B of Figure 5 displays the murder rates of white males for the same three age groups.

The 15-24 year old murder rate increases three years after crack arrives in MSAs, and increases by 51 percent eight years after crack arrives. It is important to note that the peak murder rate for this group was approximately one-eighth the rate of their black counterparts. Murder rates for white males aged 25 years and older are unchanged by the introduction of crack. Murder rates for black females are in Panel C. The rates for black female aged 15-24 and 25-39 had small increases in the years after crack arrives, although they are not affected to the same degree as males. The rates for white females are in Panel D and all groups appear to be unaffected by the emergence of crack markets.

We estimate the impact the arrival of crack on murder rates using a difference-in-difference model where individuals aged 40 and up serve as a comparison group. They were largely unaffected by the emergence of crack but should be exposed to other factors affecting overall murder rates. ${ }^{21} \mathrm{We}$ estimate separate models for 15-24 year olds and 25-39 year olds in each sex-race group.

We use a negative binomial count data model because there are zero murders in some

\footnotetext{
${ }^{20}$ The results are similar if we re-organize murder rates in terms of the arrival dates for the 41 states.

${ }^{21}$ Grogger and Willis (2000) analyzed the impact of crack on crime within a differences-in-differences framework where they used black males residing in suburban areas to control for the level of crime experienced by blacks living in the central city of the MSA. While this was likely appropriate for an analysis of crime locations, which were often concentrated in the center city, we are interested in the impact of murders and crack on human capital decisions. Therefore, individuals who reside in a suburban area but are killed in an urban area are still critically important to our analysis. Contrary to many commonly held perceptions of crack, there were significant impacts on murder outside of central areas. Figure 4c shows the change in the 15 to 24 year old black male murder rate based on a city's population. It is evident from this figure that there were large changes in the black male murder rate outside large cities suggesting that an identification strategy comparing suburban and urban areas is not appropriate in our context.
} 
MSA/year/group cells. The key variables are a treatment group identifier and dummy variables identifying periods in relation to when crack cocaine arrived. The effect of crack is estimated from the interaction between the treatment group identifier and the dummy variables spanning $0-2,3-5$, and 6-8 years after crack arrives. Covariates in the model include city and year effects, and cityspecific time trends. We also include the natural log of population for each demographic group and fix the parameter to be one, so the parameter estimates are roughly equivalent to estimates from an OLS regression with the natural $\log$ of the mortality rate as the outcome of interest. Observations are weighted by population values and we allow for arbitrary correlation in observations within an MSA.

Table 4 contains the estimates for this model, with Panel A showing results for males. In comparison to black males aged 40 years and older, there is an increase in the murder rate of black males aged 15-24 in each period after crack markets arrive, with a doubling of their murder rate six to eight years after the arrival of crack. The magnitude of this estimate corresponds closely to the unadjusted graphical evidence in Figure 5. Black males aged 25 to 39 are estimated to have a 33 percent higher murder rate six to eight years after the introduction of crack markets. The third row contains estimated coefficients for white males aged 15 to 24 , who experience a 50 percent increase in their murder rate six to eight years after crack arrives. The estimates for white males aged 25-39 years, presented in the fourth row, are one-third of this size. Virtually all the estimates in this panel are statistically significant at the five percent level.

Estimates for females are shown in Panel B. Compared to black females aged 40 plus, black females aged 15-24 and 25-39 years have statistically significant increases in their murder rates six to eight years after crack arrives of 22 and 11 percent, respectively. Coefficients on the earlier periods are smaller and statistically insignificant. White females aged 25-39 years have statistically significant increases for all three periods, although the increases never translate into an increase in the 
annual murder rate of more than one per 100,000 people.

\section{Crack Cocaine Markets and High School Graduation Rates}

If crack is responsible for the stalled progress in the closing of the black-white education gap, then its emergence in each MSA or state should be followed by worsening black educational outcomes. We investigate this using data from the 2000 Census Five Percent PUMS, and exploit differential timing in the arrival of crack markets. While we would like to know each individual's place of residence during high school, we only know current MSA/state of residence and state of birth. We will show that using current residence or location of birth for the state sample produces similar estimates, suggesting migration concerns are not having a strong impact on the results.

Our first sample contains U.S. born non-Hispanic respondents currently residing in MSAs who turned 18 between the years 1975 and 1999. Among the respondents in this sample, 80 percent resided in the MSA they lived in five years previously. ${ }^{22}$ Our next two samples use the same demographic and age restrictions but contain respondents that live in the 41 states with the largest fraction of blacks or were born in one of these states. The benefit of this sample is that it allows us to include individuals living outside of metropolitan areas. As discussed above, black males in nonmetropolitan areas experienced dramatic increases in murders over this time period. We present results assuming schooling happened either in the current state of residence or state of birth.

Figures $3 \mathrm{a}$ and $3 \mathrm{~b}$ were introduced previously and, in these graphs, we use data from the MSA-based PUMS sample to examine changes in black and white high school graduation rates in relation to when crack arrives in cities. The horizontal axis describes the number of years before or after crack first arrives in the 57 MSAs. The left vertical axis contains the percentage of white

\footnotetext{
${ }^{22}$ A specific concern may be that families move to get away from crack-related violence. Cullen and Levitt (1999) find migration in response to crime occurs by families, but they tend to stay within the same MSA.
} 
individuals that report a high school degree, while the right vertical axis provides the same information for blacks. Figure 3a describes the educational outcomes for males. The results are consistent with those in Figure 1 in that they show a convergence in white-black outcomes prior to the arrival of crack. Two years after crack arrives, the graduation rate for 18 year old black males starts to decrease. This pattern corresponds to the earlier estimates of the impact of crack on violence across different cities, given that murder rates for young black males began to increase two years after crack arrived in a city. Figure $3 \mathrm{~b}$ contains a similar analysis for females. The graduation rate of black females declines relative to whites after the arrival of crack, although this decline is smaller than for males. Figures $3 \mathrm{c}$ and $3 \mathrm{~d}$ contain the same reduced-form analysis using the PUMS sample based on state of birth, and display similar patterns to those at the MSA level.

The impact of the arrival of crack markets on graduation can be more rigorously examined in a regression context. The model must be specified in a way that captures a number of key time series features in the data, such as the convergence in test scores prior to the arrival of crack and the possible divergence in outcomes after the arrival of the drug. Since there are persistent differences in outcomes across geographic regions, races, and cohorts, the model must also control for these dimensions of the data. To capture these characteristics we use the following specification:

$$
\text { (1) } y_{i c g}=\mu_{c}+\lambda_{r g}+\text { Black }_{i c g} * \text { CappedTrend }_{c g} \beta_{1}+\text { Black }_{i c g}{ }^{*} \text { YearsAfterCrack }{ }_{c g} \beta_{2}+\varepsilon_{i c g}
$$

where $y_{i c g}$ is an indicator equal to one if person $i$ from cohort $c$ and geographic area $g$ graduated high school and zero otherwise. A complete set of fixed effects for each birth-year cohort is represented by $\mu_{c}$, a full set of geographic-specific fixed effects that are allowed to vary by race $r$ is given by $\lambda_{r g}$, and the variable Black ${ }_{i c g}$ is an indicator equal to one if the respondent is black and zero otherwise. The variable CappedTrend $_{c g}$ measures trends in high school graduation before the arrival of crack cocaine. It equals one for the cohort that turns 18 in 1973, two for the 1974 cohort, and so on, until 
the year that crack arrives in a geographic area, after which it is held constant. For example, we estimate that crack arrives in Los Angeles, Miami, and New York in 1982, so CappedTrend $d_{c g}$ is set to ten for residents in those MSAs for all years after 1982. The coefficient $\beta_{1}$ results from the interaction

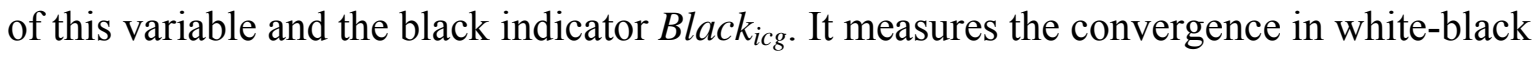
graduation rates across cohorts prior to the arrival of crack markets, so we expect $\beta_{1}$ to be positive.

There is a second trend variable named YearsAfterCrack $k_{c g}$, which also varies by cohort and location. It equals zero in all years prior to the arrival of crack, then one in the year after crack arrives, two the next year, etc. The coefficient $\beta_{2}$ from the interaction of this trend variable and the race indicator Black $k_{i c g}$ describes the deviation from trend in white-black graduation rates after the arrival of crack. ${ }^{23}$ Since crack markets emerge at different times in each MSA, the cohort effects control for age-specific secular changes in these outcomes. Under the assumption that the arrival of crack markets is not correlated with the location-specific progress in graduation rates, $\beta_{2}$ represents the causal impact of crack if there had been no further convergence in graduation rates. We also estimate a specification of equation (1) that replaces the YearsAfterCrack ${ }_{c g}$ variable with nine indicator variables that identify the year crack arrives and the eight years afterwards.

To better understand the role of the trend variables, define a variable $\operatorname{Trend}_{c}$ that equals one for the oldest cohort, two for the second, etc. If the arrival of crack had no race-specific impact on high school completion rates, then $\beta_{1}$ (the pre-crack trend) will equal $\beta_{2}$ (the post-crack trend) and Black $_{i c g}{ }^{*}$ CappedTrend $_{c g}+$ Black $_{i c g}{ }^{*}$ YearsAfterCrack $_{c g}=$ Black $_{i c g}{ }^{*}$ Trend $_{c}$. Therefore, we have specified the model to be flexible enough to measure the continued improvements for successive black cohorts if crack had no impact on high school graduation rates.

\footnotetext{
${ }^{23}$ Because crack enters cities at different times, larger values of YearsAfterCrack ${ }_{c g}$ will combine two effects. One is the long-term impact of crack and the other is the changing composition of cities. We have at most 8 years of post-crack graduation rates for all areas and therefore we delete observations for cohorts if they are 9 or more years after the arrival of crack in their MSA.
} 
Table 5 contains the key coefficients of interest from estimating equation (1) using several different samples. The first column of Panel A contains estimates from using the MSA sample of males. For each year prior to the arrival of crack, the percentage of blacks with a high school degree increased by a statistically significant 0.17 percentage points ( $\mathrm{p}$-value $<0.001$ ) compared to their white counterparts. The estimated coefficient on Black $k_{i c g}{ }^{*}$ YearsAfterCrack $_{c g}$ suggests that, after crack arrives, black males had an average annual decline in relative high school graduation rates of 0.29 percentage points. This estimate is statistically significant at a p-value of $0.01 .{ }^{24}$ The second column contains similar estimates for females using the MSA sample. While black female graduation rates also showed progress compared to whites before the arrival of crack, the estimated annual impact of crack on the probability of obtaining a high school degree for females is approximately one-third as large as the estimate for males and only statistically significant at a p-value of 0.10 .

The last four columns of Panel A contain equivalent estimates from the state PUMS sample, with results in the third and fourth columns using state of birth to define high school attendance and the final two columns using current state of residence to define high school attendance. The coefficients across both samples are remarkably similar. The estimated annual decrease in black male graduation rates after the arrival of crack is 0.34 percentage points across both samples. The impact for females is approximately one-sixth the size of the male estimate and statistically insignificant.

Panel B of Table 5 contains results for the specification of equation (1) with an indicator variable for each year after crack arrives. The estimates for males in the MSA sample is in the first

\footnotetext{
${ }^{24}$ There could be a concern that the estimated coefficients in this context are affected by changes in the educational attainment of white males. Therefore, we estimated a specification of the model for a sample including white females and black males. White females were essentially unaffected by the emergence of crack cocaine, but they are also unaffected by other factors that influence the educational attainment rates of all males regardless of race. For the MSA sample, the estimated coefficient (standard error) on the capped trend and post-crack index from this model is $0.0015(0.0004)$ and $-0.0027(0.0009)$ respectively. An alternate comparison group contains black females, who are exposed to similar non-crack related race-specific shocks but are not as affected by crack as black males. The estimate for the capped trend using black females as the comparison group is 0.0002 (0.0004). The small size and lack of statistical significance for this pre-trend should not be surprising since both groups demonstrated similar progress in graduation rates over this time period. The post-crack index estimate (standard error) is -0.0016 (0.0008), which is smaller in magnitude than the estimate using either white males or females, but still statistically significant at a p-value of 0.05 .
} 
column, and shows statistically significant decreases in high school graduation rates that begin five years after the emergence of crack in an MSA. Members of this cohort were entering high school as crack markets emerged in their cities. A similar pattern is seen for the state-level male results, irrespective of the method used to assign high school location. The estimates for females in the MSA sample are small in magnitude and not statistically significant at conventional levels except for the coefficients for the first and seventh year after crack arrives. The year-by-year coefficients for females in the state sample are generally positive and are sporadically statistically significant.

While the location fixed effects control for time-invariant differences across areas, it is possible that changing economic and community characteristics affected graduation rates. To account for the potential impact of these factors, we estimated a specification of equation (1) that includes covariates that vary by state, race and year, such as the educational status of mothers, the percentage of children without a father present in the home, median family income, and the state unemployment rate. $^{25}$ These covariates are available from 1978 . We also include race-specific measures of the school environment averaged to the state level including current expenditures per student, the racial fractionalization of the school, and the within-district Gini coefficient in family income. ${ }^{26}$ The full set of results from this specification is available in an online appendix. The inclusion of covariates decreases the magnitude of the male pre-trend estimate for males by approximately 21 percent, which is similar to the results in Cook and Evans (2000) which found that school and demographic factors can explain 25 percent of the convergence in test scores. The estimated impact of crack arrival on black male graduation rates decreases by only 13 percent and remains statistically significant at a pvalue of 0.001 . The inclusion of covariates has little impact on the estimates for females, though the

\footnotetext{
${ }^{25}$ The first three variables were calculated from the March CPS while the state unemployment rate is calculated from all monthly CPS samples.

${ }^{26}$ The variables are calculated from the data in Corcoran and Evans (2010) which is a panel data set of unified school districts from 1970/1980/1990/2000. To get race-specific state level averages, we aggregate data from the district to the state level using the number of whites and blacks in the district as the weight. We interpolate data between census dates.
} 
estimated impact for females in MSAs falls to -0.0009 (0.0006) and is no longer statistically significant. These additional results suggest that the results in Table 5 are unlikely to be due to changing socioeconomic and school-level characteristics.

To examine the robustness of our findings to alternate dating mechanisms, we examine equation (1) using the crack arrival dates Grogger and Willis (2000) obtained from police chiefs in 25 cities. The male estimate (standard error) for $\beta_{2}$ using these dates is a statistically significant -0.0020 $(0.0011) .^{27}$ The corresponding estimate (standard error) for women is $-0.0006(0.0009)$.

\section{The Local Severity of Crack Markets and the Educational Attainment of Black Males}

The results above show a link between the arrival of crack market and educational outcomes. In order to understand the potential mechanisms underlying this stalled progress, we construct measures of the intensity of the effects of these markets based on murder and prison intake rates.

\section{a. The Rapid Rise in the Murder Rate}

If the perceived mortality risk following the introduction of crack is affecting the educational outcomes of young black males, then graduation should be correlated with the murder rates of a reference group. As a measure of perceived mortality risk, we construct three-year averages of the murder rates individuals witness for their own race and sex during high school. For example, for a black male in the cohort that turns 18 in 1980, the perceived mortality risk is constructed using black male murder rates from 1978 to 1980 . In order to avoid a potential mechanical correlation between educational outcomes and homicides, we use the murder rates of 20-24 year olds. ${ }^{28}$

\footnotetext{
${ }^{27}$ Estimating a similar model using the DAWN-based arrival dates for 22 cities, the value of $\beta_{2}$ for males is $-0.0014(0.0009)$. The estimate for females is $-0.0003(0.0005)$.

${ }_{28}$ The results are robust to using the murder rate for individuals aged 15 to 24 .
} 
Table 6 contains the estimates from a model that regresses high school graduation rates on the average murder rates during high school, cohort fixed effects, and sex- and race-specific geographic area effects. The first panel of Table 6 contains the estimates at the MSA level. Results are provided for two samples: the 57 MSA sample and a broader sample of the 174 largest MSAs. ${ }^{29}$ The first two columns contain estimates for both sexes using these two samples, and show there is a negative relationship between murder rates and graduation that is statistically significant at the one percent level. The numbers in square brackets (below the standard errors) are the total estimated effects on black high school graduation using the changes in murder rates from 1983 to $1993 .{ }^{30}$ Within the 57 MSA sample, this increase was associated with a 0.5 percentage point decrease in black male graduation rates. The broader sample of MSAs returns a similar effect of 0.6 percentage points.

We estimate this model separately for males and females. The third and fourth columns contain results for males that also show a negative and statistically significant relationship between murder rates and graduation. From 1983 to 1993, the 20-24 year old black male murder rate increased from 91.6 to 192.1 per 100,000 residents. In the 57 MSA sample, the 1983-1993 increase was associated with a 0.9 percentage point decrease in high school graduation among black males. For the broader sample, the estimated decrease due to the change in murder rates was 1.2 percentage points. The final two columns of the top panel of Table 6 contain the estimates for females. The impact of murder rates on female high school graduation is small in magnitude and statistically insignificant.

The second panel of Table 6 contains estimates for the state PUMS sample. Estimates are provided based separately on respondents' state of birth and state of residence for both sexes, males only, and females only. All of the coefficients are statistically significant at the five percent level, and

\footnotetext{
${ }^{29}$ The sample of 174 MSAs comprises all cities that can be consistently identified in the PUMS and the MCOD data over the entire time period of the analysis.

${ }^{30}$ The murder rate for 20-24 year old blacks increased from 54.8 to 107.1 per 100,000 people over this period in the 57 MSA sample. The increase in the broader sample was similar.
} 
the results are not affected by how high school location was assigned. The effect of 1983-1993 changes in murder rates on high school graduation is estimated to be a decline of 0.9 percentage points, while the effect for males is a decline of nearly two percentage points. This is not surprising given that many smaller places experience large increases in the black male murder rate. The estimated effect for women is positive and statistically significant, although the small change in the murder rate means the marginal effect for females was only 0.3 percentage points.

\section{b. Increased Incarceration of Black Males}

Changes in the probability of incarceration would further limit the expected benefits from investments in human capital. ${ }^{31} \mathrm{We}$ analyze the impact of this on educational attainment using the state PUMS sample with high school attendance defined as the state of birth. ${ }^{32}$ Table 7 contains estimates from a regression of male graduation rates on the race-specific NCRP prison intake rate of 20 to 24 year olds when a respondent turned 18 . The regression also includes state $\mathrm{x}$ race fixed effects, and cohort fixed effects. ${ }^{33}$ Table 7 shows the estimates from the full sample of states reporting NCRP prison intake data in any year. The marginal effect for black males in brackets in the first column suggests that the change in average intake rate from 1983 to 1993 is responsible for a three percentage point decrease in high school graduation rates. This estimated effect is slightly larger than the murder rate estimates in the previous table. ${ }^{34}$

In order to determine the independent impacts of murder and prison rates, the third column of

Table 7 contains a specification with both of these indices included as independent variables. Both of

\footnotetext{
${ }^{31}$ Incarceration potentially has direct effects on high school graduation as measured here, as approximately one-tenth of GEDs are obtained in prison (Heckman and Lafontaine, 2010). This may lead to an understatement of any negative relationship between incarceration rates and high school graduation.

${ }^{32}$ As for the results we have presented so far, similar results are obtained using state of current residence.

${ }^{33}$ For the murder rate we used a three year moving average of the murder rate when a cohort turns 18 . Because we have so few years of data on prison entry rates, we use as the covariate the prison entry rate the year a cohort turned 18 .

${ }^{34}$ The second column of estimates replicates the murder rate regressions in Table 6 using the states in the NCRP. In the NCRP sample the marginal effect of the murder rate is a 2.4 percentage point change in graduation rates - slightly larger than the earlier estimates.
} 
these factors are independently predictive of changes in the high school graduation rate. The marginal effects for black males suggests that the combined impact of these factors is a 3.5 percentage point decline in high school graduation rates, with a larger impact from the prison intake variable than the murder rate variable. ${ }^{35}$

\section{c. An Alternative Measure of the Local Severity of the Crack Epidemic}

Fryer et al. (forthcoming) constructs an index of the severity of crack in 144 cities and in states. ${ }^{36}$ It is composed of factors such as homicides, cocaine arrests, cocaine-related emergency department measures, cocaine seizures by the Drug Enforcement Agency, and newspaper articles discussing crack cocaine. ${ }^{37}$ The index provides a summary measure of social indicators that may have been affected by crack markets together with indicators of crack market activity and awareness.

We used the PUMS MSA sample to estimate the relationship between the high school graduation of blacks and the Fryer et al. index. We merge their index into the data based on the year each cohort turned 18, so a black respondent from New York that turns 18 in 1986 received the index number for that year. We interact the index with the black identifier, and include fixed effects for cohorts and MSA by race fixed effects. The estimated coefficient (standard error) on this index for such a model is $-0.0081(0.0018)$ for males and $-0.0013(0.0011)$ for females. From 1983 to 1993, the Fryer et al. index increased by 1.85 points, suggesting that crack was associated with roughly a 1.5 percentage point decrease in black male graduation rates. This is smaller than our estimate of a 2.4

\footnotetext{
${ }^{35}$ The appendix contains estimates for only the states providing data in each year. For this sample, the combined marginal effect of changes in murder and incarceration rates is a 5.0 percentage point decrease, which partly comes from the higher murder and incarceration rates in that selected sample of states.

${ }_{37}^{36}$ Among the 57 MSAs in our reduced-form analysis, 52 are included in the Fryer et al. index.

${ }^{37} \mathrm{Newspaper}$ articles are included in this measure if they contain the name of city along with both the terms crack and cocaine.
} 
percentage point decline in black male graduation rate eight years after crack arrived. ${ }^{38}$

\section{Understanding the Mechanisms}

In this section, we consider the explanatory power of changes in human capital investment and what other crack-related changes that may have affected educational attainment. We show it is plausible that changing returns to education accounts for a substantial part of the observed decline in the high school graduation rates of black males, as well as the connection between graduation and both homicide and incarceration rates. We then consider alternative explanations and show that, while they may have some effect on white-black educational differences, it seems unlikely they are the primary mechanisms through which the crack epidemic affected educational outcomes.

\section{a. The Potential Role of Human Capital Investment}

We start with the relationship between homicides and high school graduation. The various estimates suggest that a 0.1 percentage point increase in the annual risk of 20-24 year old black males being murdered generally results in a decline in the high school graduation of black males of 1-2 percentage points. It is important to note two things when it comes to interpreting changes in annual homicide rates. The first is that annual changes lead to much larger cumulative effects. While the annual homicide risk for black males aged 20-24 in both samples increased by 0.1 percentage points between 1983 and 1993, the cumulative risk that a 20 year old black male would be murdered before reaching 25 years of age increased by 0.44 percentage points, and the chance of dying increased by

\footnotetext{
${ }^{38}$ The difference likely results from the fact that most cities experience a large increase in their index values in 1986 - a degree of uniformity that is not found in our measure or in a wide variety of ethnographic accounts. To demonstrate this point we estimated an OLS model of the 1980 to 1999 city-level index on a full set of city and year indicator variables using a sample of the 51 cities jointly identified for our measure and the index. The estimated coefficients (standard errors) from a model on the indicator variables for the years 1983, 1984, 1985, 1986, and 1987 are $0.124(0.04), 0.2(.045), 0.309(0.051), 0.966(0.1113)$, and $1.167(0.118)$ respectively. This appears to be driven by a surge in media coverage of the crack epidemic in 1986. The increased attention appears to result from several factors occurring in 1986 such as the CBS documentary 48 Hours on Crack Street, the overdose death of basketball star Len Bias, and President Ronald Reagan's re-declaration of a war on drugs.
} 
0.54 percentage points over the same period. ${ }^{39}$ Changes in mortality risks were also occurring among those outside of the 20-24 age range, as shown in Figures 2 and 4. It is informative to again consider 15 year old black males assessing cumulative risks in terms of contemporaneous death rates of older black males. Their probability of dying by age 30 increased by 1.6 percentage points between 1983 and 1993. If life expectancy is censored at 65, as a measure of changes to working life, then between 1983 and 1993, work life declined by 0.9 years (1.5 percent) from 58.1 to 57.2 years. ${ }^{40}$

A second point is that during periods of increased gun homicides, there should be increased rates of non-fatal gunshots, which may have distinct effects on earnings. ${ }^{41}$ Cook (1985) estimates that the death rate from gun assaults is approximately 15 percent, which suggests there are approximately 5.7 non-fatal shootings for each fatality. Many result in hospitalizations, and some lead to long-term impairments like brain trauma and spinal cord injuries. Studies have estimated that aggregate earnings losses from non-fatal gunshot wounds are 5-40 percent as large as the losses associated with gun-related fatalities (Max and Rice, 1993; Miller and Cohen, 1997; Corso et al. 2007).

When the 1.5 percent decline in expected working life due to an increase in murders is scaled to account for the additional effect of gunshot wounds, then expected working life may have declined by 1.5-2.1 percent during this period. The implied of elasticity of high school graduation to this changing expectancy of working life is in the range of 0.5 to 1.3 . This calculation is useful as it is the same one made by Jayachandran and Lleras-Muney (2009) in understanding the relationship between maternal mortality declines in Sri Lanka and human capital accumulation (measured in terms of schooling years and literacy). Their implied elasticity is between 0.6 and 1 . Another comparison is available from the work by Wilson, Wolfe and Haveman (2005) who examined how adolescents'

\footnotetext{
${ }^{39}$ As before, this basing risk on the contemporaneous age-specific mortality rates for an individual's same demographic group.

${ }^{40}$ For white males, over the same period the contemporaneous risk of dying by age 30 decreased by 0.1 percentage points, from 2.2 to 2.1 percent, 65 -censored life expectancy increased by 0.09 years, or 0.16 percent.

${ }^{41}$ Between 1983 and 1993, there is a correlation of 0.98 between the annual number murders with firearms and the annual number assaults with firearms recorded in the Uniform Crime Reports (http://bjs.ojp.usdoj.gov/content/glance/tables/guncrimetab.cfm).
} 
income expectations through observing the incomes of slightly older individuals with similar characteristics affect high school completion. The authors find that a 10 percent increase in the relative net present value (NPV) that the reference group receives from graduating high school increases high school graduation by $1.5-2$ percentage points. ${ }^{42}$ Applying changing mortality rates between 1983 and 1993 to their earnings values would suggest a decrease in the relative NPV of graduating high school by 2-3 percent, although allowing for risk aversion or for the mortality risks to be concentrated among youth on the margin between graduating and dropping out of high school could make the effect on subjective expectations on high school graduation much higher (Groot and Oosterbeek, 1992; Brown, Fang and Gomes, 2012). This is particularly so given that the increase in homicide rates was concentrated in particular locations.

In total, these exercises indicate the possibility that the relationships identified through the homicide rate is based on the changing expectation about the returns to educational attainment. The labor market impacts of incarceration also suggest the estimates presented in Table 7 may be largely related to lowering returns to education. The direct incapacitation effects of incarceration obviously prevent work, and increasing sentence lengths were the primary driver of the growth in incarceration between 1980 and 1996 (Blumstein and Beck, 1999). There is also evidence that ex-prisoners have long-term difficulties in finding employment and slower earnings growth. For black males, recent studies have found incarceration lowers subsequent employment by approximately 12 to 25 percent (Western and Beckett, 1999; Western, 2006; Raphael, 2007). Job quality is also affected, with

\footnotetext{
${ }^{42}$ The underlying model assumes no liquidity constraints and that schooling has no direct effects on consumption, so that individuals seek to maximize net present value of income. With mortality risks, the value of graduating high school becomes: $V_{g}=-C+$

$\sum_{t=0}^{T} \beta^{t} E\left[\left[y_{g t}-y_{d t}\right] \prod_{k=0}^{t}\left(1-\right.\right.$ deat $\left.\left._{k}\right)\right]$, where $g$ denotes graduating and $d$ denotes dropping out, and $t$ denotes years up to end working life $T$. The pecuniary and non-pecuniary costs are given by $C$. The remaining terms represent the expected value of earnings gains, which is determined by the expected income differences between graduating and dropping out $\left[y_{g t}-y_{d t}\right]$ conditional on surviving to year $t$. While we assume $C$ is not changing for the moment, most of the subsequent mechanisms would operate through this term. Income from dealing crack could have increased $y_{d t}$. We take the earnings values from the top panel of Table 1 in their paper. The range comes from Wilson et al. (2005) and ignoring income before age 19 or, alternatively, assuming that high school dropouts have flat earnings between 15 and 19 years of age.
} 
Western (2002) estimating that incarceration lowers wage growth by approximately 30 percent. Bonczar (2003) estimates that black males' lifetime risk of going to prison changed from 13 to 31 percent between 1979 and $1997 .{ }^{43}$ The magnitude of the increases in incarceration, and the labor market consequences of these changes, suggest it is plausible that the high school graduation rates of black males declined by 2-3 percentage points between the early 1980s and mid 1990s.

\section{b. What is the Role of Income Generation through Drug Dealing while of School Age?}

The direct substitution of school for drug dealing is quite different from the other changes we believe are affecting returns to schooling. We would ideally like detailed information that would allow us to separate the income-generating effects of crack cocaine markets from violence and incarceration. Per-capita emergency department (ER) mentions of cocaine are a noisy measure of MSA-level consumption, which should also be related to the income-generating opportunities from being involved in distributing crack. These have been published in Drug Abuse Warning Network reports, the surveillance system that Grogger and Willis (2000) used to create one of their set of crack arrival dates. We located reports covering 1978-1999 and used them to calculate rates of cocaine ER mentions for 20 of the 57 MSAs in our sample.

When we combine murder rates with ER mentions during high school, we find a negative relationship between cocaine ER mentions and high school graduation in the whole sample and in a sample of males, although these estimates are imprecise when combined with murder rates (respective t-statistics of 0.9 and 1.5). Some effects of the size of the crack market on educational outcomes may have been possible to identify in a larger sample, or with better consumption or sales data. Having both ER mentions and murder rates in the same regression does not change the

\footnotetext{
${ }^{43}$ These figures, and the dataset we use, do not include offenders in jail. Caulkins and Chandler (2006) estimate that including jailed drug offenders increases incarceration estimates by 40 percent.
} 
magnitudes of the negative relationship between murder rates and high school graduation for the sample or for a sample of males. The only difference is that, with only $20 \mathrm{MSAs}$, the coefficients are statistically significant at the 10 percent level; this is the case with or without the inclusion of cocaine ER episodes as an additional variable. ${ }^{44}$

Outside of this coarse measure of market size, we must rely on insights from the literature on the returns to drug dealing to understand its likely role in our estimates. Studies use a variety of data collection methods including criminal justice records and school-based surveys (Reuter et al., 1990), financial records from a gang selling crack cocaine (Levitt and Venkatesh, 2000), and ethnographic observations of drug markets (Johnson et al., 2000). While these studies do not necessarily provide a representative picture of crack cocaine dealing, several regularities across studies suggest that it is unlikely the decline in educational attainment for black males after the arrival of crack is strongly connected to school-age youths selling crack cocaine.

One is that crack dealing was predominantly a part-time activity that did not conflict with formal employment or high school attendance. Johnson et al. (2000) observed 300 participants in crack markets in New York and found most used it as a sporadic way to earn income. Levitt and Venkatesh (2000) reported that members of a Chicago crack-selling gang most commonly worked four times a week for four hours each time, that the pay was low, and that many held legitimate jobs. Reuter et al. (1990) examined arrest records in the DC between 1987 and 1989 and found the employment rates of individuals arrested for drug selling were similar those arrested for non-drug offenses. In a follow-up survey, they found that individuals working more intensively in the formal labor market were more active in selling crack and that their income from dealing drugs was limited.

Second, studies reporting the ages of crack sellers suggest most were of post-school age.

\footnotetext{
${ }^{44}$ These results are presented in an online appendix.
} 
Johnson et al. (2000) reported that many inner-city youths did not sell crack and those that did were less skilled and more likely to be arrested. The General Accounting Office (1989) found that crack dealers were most commonly in their early 20s, while Reuter et al. (1990) found that arrests for drug selling in DC peaked at 24 years of age. The murder rate changes among 15-24 year old black males are mainly due to the murder rate changes of 19-24 year olds, so to the extent murders reflect participation in crack markets then this indicates more activity among post-school age children.

\section{c. Differential Crack Cocaine Use as an Alternate Mechanism}

A potential mechanism behind the changes in educational attainment is the use of crack cocaine among school-age teens. This is an unlikely explanation for several reasons. First, crack use by individuals under the age of 18 was low over this period. According to the 1990 Monitoring the Future Survey, 1.2 percent of high school seniors reported crack cocaine use in the past year and 0.7 percent reported use in the previous year (Johnston et al., 1991). Second, what data exists suggests that blacks in this age range used crack at rates similar to that of whites. According to data on drug utilization by age from the National Household Survey of Drug Abuse in 1995, the lifetime crack use for 16 to 17 years olds was 5.1 percent for whites compared to 4.2 percent for blacks. While participation rates may mask underlying differences in cocaine dependence, treatment of teenagers for smokeable cocaine was relatively rare. ${ }^{45}$ Low utilization rates and no differential use by race means that crack use is not a confounding factor driving the results above.

\section{d. The Roles of Changing Family Structure and School Quality}

\footnotetext{
${ }^{45}$ According to the Substance Abuse and Mental Health Services Administration's (SAMHSA) Treatment Episode Dataset for 19921995 (the first years where treatment data are available), the rate of crack abuse requiring treatment was less than one percent for children aged 17 years or less and a further two percent for those aged 18 or 19 (SAMHSA, 1997).
} 
Another possibility is that, rather than reacting to increased mortality or prison risk, these changes in educational outcomes reflect changes in family structure or differential school quality. If changes in family structure were actually responsible for the decreased educational outcomes among older black males than results of similar magnitude should be found for females and younger black males. Both the reduced-form and the murder rate results above show larger and more precise effects for males than for females. The lack of an effect for females limits the potential for changes in school quality or family structure to account for educational patterns after the arrival of crack.

There could be a remaining concern that the impact of absent fathers or other family-level changes could differentially affect males as compared to females. If this were the case, then we should expect decreases in educational attainment for black males at all ages, but this is not the case. Some evidence on this point can be found in patterns for the NAEP-LTT standardized test scores. These math and reading tests have been given to nine, 13, and 17 year olds every two to five years since the early 1970 s, and tests have not changed over this period. ${ }^{46}$ In Figures $6 \mathrm{a}$ and $6 \mathrm{~b}$ we present the percentage differences in white and black scaled scores by age for reading and math, respectively. The filled year markers represent the years in which NAEP tests were administered. Among 17-yearolds, the reading scores of whites were 22 percent higher than of blacks in $1971 .{ }^{47}$ This gap fell to seven percent in 1988 , and then rose to 11 percent by 2004 . For this same age group, the gap in math test scores halved from 14 to seven percent between 1978 and 1990, and then rose to 10 percent by $2004 .^{48}$ The trends for 13-year-old reading and math scores are similar, with white and black test scores converging until the late 1980 s and diverging after. The trends for nine year olds are different,

\footnotetext{
${ }^{46}$ More information about the NAEP LTT is available at http://nces.ed.gov/nationsreportcard/ltt/.

${ }^{47}$ Although we do not show it here, all of the convergence in test scores though the 1980s is due to rising black test scores. Scores for white students have changed little over this period (Neal, 2006; Magnuson and Waldfogel, 2008).

${ }^{48}$ Only those attending school are tested, so the 17 year old sample is missing individuals who have dropped out of high school. The decreasing high school graduation rates of blacks relative to whites in the 1990s should remove 17 year old black students of belowaverage ability and bias the results away from finding a widening test score gap.
} 
however, with the gap mainly decreasing throughout the entire time period. This is particularly evident for math scores. The lack of a similar impact in test scores for younger black students than is observed for older black males suggests that changes in family structure are not primary drivers of the stalled progress.

\section{Conclusion}

The emergence of crack cocaine markets in an area generates three primary impacts for young black males: an increased murder rate, an increased prospect of incarceration, and an increased opportunity for employment outside of the formal sector. Each of these factors lowers the potential return from an investment in human capital and therefore our estimates of reduced schooling provide additional evidence of individuals investing in education as outlined in Becker (1964).

From 1970 to 1985 the percentage of black males who received a high school degree increased by an average of 0.4 percentage points per year. As a testament to the pace of white-black convergence prior to the arrival of crack, if black males had continued this historic progress, by 1996 their high school attainment rate would have been roughly equal to the rate for white males. The results above show that the introduction of crack cocaine to a city reversed this progress and that the responses to changing murder and prison intake rates reduced the percentage of black males with a high school degree by 3.5 percentage points. Over the period of greatest post-crack decline in black high school graduation rates, 1986 to 1996 , there was a 4.8 percentage point decrease in the percentage of black males with a high school degree. Depending upon assumptions about the continuation of the historical convergence, we explain between 40 and 73 percent of the decline in educational achievement among black males between 1986 and 1996.

By the late 1990s and early 2000s, much of the violence associated with crack markets had 
subsided. Law enforcement accounts suggest that this was the result of crack turning into a stable drug market where property rights were relatively well established. This decline in the murder rate was however not matched by a similar decrease in the prison intake rate. In 1999, 3.5 percent of black males between the ages of 20 to 24 in our data entered a federal or state prison facility. This demonstrates that a continued disruption from some portion of the crack cocaine markets. Panel C of Figure 1 contains the high school attainment rate by race and sex from 1967 to 2004 . The period of reduced violence in the late 1990s was matched by a slowing of the decline in the educational attainment of black males. From 1986 to 1996 the high school attainment rate of black males fell by an average of 0.6 percentage points a year. However, from 1996 to 2004 this rate fell by only 0.097 percentage points a year. While this was not a return to the historical growth throughout the 1970s, it certainly was a break from the declining trend during the height of the crack epidemic. The failure to return to growth could be a sign of a new equilibrium that could result from factors such as decreased intergenerational transfers in education from parents, siblings, or other relatives. Further research is necessary to determine the factors underlying the current trends in black educational attainment. 


\section{References}

Agar, Michael. 2003. "The Story of Crack: Towards a Theory of Illicit Drug Trends." Addiction Research and Theory, 11(1): 3-29.

Armor, David J. 1992. "Why is Black Educational Achievement Rising?” Public Interest, 108(Summer): 65-80.

Anderson, Elijah. 1994. "The Code of the Streets.” Atlantic Monthly, 273: 81-94.

Becker, Gary S. 1964. Human Capital. New York: Columbia University Press.

Ben-Porath, Yoram. 1967. "The Production of Human Capital and the Life Cycle of Earnings." Journal of Political Economy 75(4): 352-65.

Bjorklund, Anders, Mikael Lindahl, Erik Plug. 2006. "The Origins of Intergenerational Associations" Lessons from Swedish Adoption Data.” Quarterly Journal of Economics, 121(3): 999-1028.

Blumstein, Alfred. 1995. "Youth Violence, Guns, and the Illicit-Drug Industry." The Journal of Criminal Law and Criminology, 86(1): 10-36.

Blumstein, Alfred, and Allen J. Beck. 1999. "Population Growth in U.S Prisons, 1980-1996." Crime and Justice 26: 17-61.

Boggess, Scott, and John Bound. 1997. "Did Criminal Activity Increase During the 1980s? Comparisons across Data Sources.” Social Science Quarterly, 78(3): 725-39.

Bonczar, Thomas. 2003. "Prevalence of Imprisonment in the U.S. Population, 1974-2001." Bureau of Justice Statistics Special Report. Washington DC: United States Department of Justice: 1-12.

Borowsky, Iris, Marjorie Ireland, and Michael Resnick. 2009. "Health Status and Behavioral Outcomes for Youth Who Anticipate a High Likelihood of Early Death,” Pediatrics, 124(1): e81-e87.

Boozer, Michael A., Alan B. Krueger, and Shari Wolkon. 1992. "Race and School Quality Since Brown v. Board of Education.” Brookings Papers on Economic Activity - Microeconomics: 269-326.

Brown, Jeffrey, Chichun Fang, and Francisco Gomes. 2012. "Risk and Returns to Education." NBER Working Paper No. 18300.

Caulkins, Jonathan P. and Sara Chandler. 2006. "Long-Run Trends in Incarceration of Drug Offenders in the US." Crime and Delinquency, 52(4): 619-641.

Caulkins, John P., Bruce Johnson, Angela Taylor, and Lowell Taylor. 1999. "What Drug Dealers Tell Us About Their Costs of Doing Business.” Journal of Drug Issues, 29(2): 323-340.

Chay, Kenneth Y., Jonathan Guryan, and Bhashkar Mazumder. 2009. "Birth Cohort and the Black-White Achievement Gap: The Roles of Access and Health Soon After Birth." Federal Reserve Bank of Chicago Working Paper 08-20. 
Chicoine, Luke. 2012. "AIDS Mortality and its Effect on the Labor market: Evidence from South Africa." Journal of Development Economics, 98(2): 256-69.

Cook, Michael D., and William N. Evans. 2000. "Families or Schools? Explaining the Convergence in White and Black Academic Performance." Journal of Labor Economics, 18 (4): 729-54.

Cook, Philip J. 1985. "The Case of the Missing Victims: Gunshot Woundings in the National Crime Survey." Journal of Quantitative Criminology, 1: 91-102.

Corcoran, Sean, and William N. Evans. 2010. "Income Inequality, the Median Voter, and the Support for Public Education.” NBER Working Paper No. 16097.

Corso, Phaedra, James Mercy, Thomas Simon, Eric Finkelstein, and Ted Miller. 2007. "Medical Costs and Productivity Losses Due to Interpersonal and Self-Directed Violence in the United States." American Journal of Preventive Medicine, 32(6): 474-482.e2.

Cullen, Julie and Steven Levitt. 1999. "Crime, Urban Flight, and the Consequences for Cities." Review of Economics and Statistics, 81(2): 159-169.

Derlet, Robert W., and Timothy E Albertson. 1989. "Emergency Department Presentation of Cocaine Intoxication.” Annals of Emergency Medicine, 18(2): 182-186.

Fagan, Jeffrey, and Ko-Lin Chin. 1989. "Initiation Into Crack and Cocaine: A Tale of Two Epidemics." Drug Problems, 16: 579-617.

Fortson, Jane G. 2011. "Mortality Risk and Human Capital Investment: The Impact of HIV/AIDS in SubSaharan Africa.” Review of Economics and Statistics 93 (1): 1-15.

Fryer, Ronald G. Jr., Paul S. Heaton, Steven D. Levitt, and Kevin M. Murphy. Forthcoming. "Measuring Crack Cocaine and Its Impact." Economic Inquiry.

Gladstein, Jack, Elisa Rusonis, Felix Heald. 1992. "A Comparison of Inner-City and Upper-Middle-Class Youth's Exposure to Violence." Journal of Adolescent Health, 13(4): 275-280.

Grogger, Jeff, and Michael Willis. 2000. "The Emergence of Crack Cocaine and the Rise in Urban Crime Rates.” Review of Economics and Statistics, 82(4): 519-29.

Groot, Wim and Hessel Oosterbeek. 1992. "Optimal Investment in Human Capital Under Uncertainty." Economics of Education Review, 11(1): 41-49.

Heckman, James J. and Paul A LaFontaine. 2010. "The American High School Graduation Rate: Trends and Levels." Review of Economics and Statistic,s 92(2): 244-262.

Jencks, Christopher, and Meredith Phillips, eds. 1998. The Black-White Test Score Gap. Washington, DC: Brookings Institution.

Jayachandran, Seema, and Andriana Lleras-Muney. 2009. "Life Expectancy and Human Capital Investments: Evidence from Maternal Mortality Declines.” Quarterly Journal of Economics, 124: 349-97. 
Jaynes, Gerald David, and Robin Murphy Williams, eds. 1989. A Common Destiny: Blacks and American Society. Washington, DC: National Academy Press.

Johnson, Bruce D., Eloise Dunlap and Sylvie C. Tourigny. 2000. "Crack distribution and Abuse in New York." In: Mangai Natarajan and Mike Hough, eds. Illegal Drug Markets: From Research to Prevention Policy. Monsey, NY: Criminal Justice Press: 19-57.

Johnston, Lloyd, Patrick O'Malley, and Jerald Bachman. 1991. Drug Use Among American High School Seniors, College Students, and Young Adults. Bethesda, MD: National Institute on Drug Abuse, US Department of Health and Human Services.

Levitt, Steven and Sudhir Alladi Venkatesh. 2000. “An Economic Analysis of a Drug-Selling Gang's Finances.” Quarterly Journal of Economics 115(3): 755-789.

Magnuson, Katherine A., and Jane Waldfogel, eds. 2008. Steady Gains and Stalled Progress: Inequality and the Black-White Test Score Gap. New York: Russell Sage Foundation.

Massing, Michael. 1989. “Crack’s Destructive Sprint Across America.” New York Times Magazine, November 27, 2011. http://nytimes.com/1989/10/01/.../crack-s-destructive-sprint-across-america.html

Max, Wendy and Dorothy Rice. 1993. "Shooting in the Dark: Estimating the Cost of Firearm Injuries." Health Affairs, 12(4): 171-185.

McDade, Thomas, Laura Chyu, Greg Duncan, Lindsay Hoyt, Leah Doane, and Emma Adam. 2011. "Adolescents' Expectations for the Future Predict Health Behaviors in Early Adulthood," Social Science and Medicine, 73: 391-398.

Miller, Ted and Mark Cohen. 1997. "Cost of Gunshot and Cut/Stab Wounds in the United States, with some Canadian Comparisons." Accident; Analysis and Prevention, 29(3): 329-341.

Neal, Derek. 2006. "Why Has Black-White Skill Convergence Stopped?" Handbook of the Economics of Education, 1: 512-76.

Nguyen, Quynh, Jon Hussey, Carolyn Halpern, Andres Villaveces, Stephen Marshall, Arjumand Siddiqi, and Charles Poole. 2012. "Adolescent Expectations of Early Death Predict Young Adult Socioeconomic Status," Social Science and Medicine, 74(2012): 1452-1460.

Osofsky, Joy D., Sarah Wewers, Della M. Hann, and Ana C. Fick. 1993. "Chronic Community Violence: What is Happening to Our Children?." Psychiatry, 56 (1): 36-45.

Oster, Emily, Ira Shoulson, and Ray Dorsey. 2012. "Limited Life Expectancy, Human Capital and Health Investments: Evidence from Huntington Disease. Working Paper, University of Chicago Booth School of Business.

Raphael, Steven. 2007. "Early Incarceration Spells and the Transition to Adulthood." In The Price of Independence: The Economics of Early Adulthood, Edited by Sheldon Danziger and Cecilia Elena Rouse. New York: Russell Sage Foundation: 278-306. 
Reuter, Peter, Robert MacCoun, Patrick Murphy, Allan Abrahamse, and Barbara Simon. 1990. Money from Crime. A Study of the Economics of Drug Dealing in Washington D.C. Santa Monica, CA: RAND Corporation.

Rivkin, Steven G. 1995. "Black/White Differences in Schooling and Employment." Journal of Human Resources, 30(4): 826-852.

Ruggles, Steven, J. Trent Alexander, Katie Genadek, Ronald Goeken, Matthew B. Schroeder, and Matthew Sobek. 2010. Integrated Public Use Microdata Series: Version 5.0 [Machine-readable database]. Minneapolis: University of Minnesota.

Sacerdote, Bruce. 2007. "How Large are the Effects from Changes in Family Environment? A Study of Korean American Adoptees.” Quarterly Journal of Economics, 122(1): 119-157.

Schubiner, Howard, Richard Scott, and Angela Tzelepis. 1993. "Exposure to Violence Among Innercity Youth.” Journal of Adolescent Health, 14: 214-219.

Stoddard, Sarah, Susan Henly, Renee Sieving, and John Bolland. 2011. "Social Connections, Trajectories of Hopelessness, and Serious Violence in Impoverished Urban Youth," Journal of Youth and Adolescence, 40: 278-295.

Substance Abuse and Mental Health Services Administration, Office of Applied Studies. 1997. National Admissions to Substance Abuse Treatment Services (TEDS) 1992-1995, Advance Report No. 12, Rockville, MD: SAMHSA.

U.S. Department of Health and Human Services. 1991. Morbidity and Mortality Weekly Report: WeaponCarrying Among High School--United States, 1990. Washington, DC: U.S. Department of Health and Human Services.

U.S. General Accounting Office. 1989. Nontraditional Organized Crime: Law Enforcement Officials' Perspective on Five Criminal Groups. Washington, DC: U.S. Government Printing Office.

Western, Bruce. 2002. “The Impact of Incarceration on Wage Mobility and Inequality." American Sociological Review, 67(4): 526-546.

Western, Bruce. 2006. Punishment and Inequality in America. New York: Russell Sage Foundation.

Western, Bruce and Katherine Beckett. 1999. "How Unregulated is the U.S. Labor Market? The Penal System as a Labor Market Institution.” American Journal of Sociology, 104(4): 1030-1060.

Wilson, Kathryn, Barbara Wolfe, and Robert Haveman. 2005. "The Role of Expectations in Adolescent Schooling Choices: Do Youths Respond to Economic Incentives.” Economic Inquiry, 43(3): 467-492.

Witkin, Gordon. 1991. “The Men Who Created Crack.” U.S News and World Report, 111(8): 44-60. 
Figure 1 High School Completion Rates by the Year each Cohort Turns 18 By Race and Sex, 2005-2009 American Community Survey

A: High School Graduation Rates, by Race and Cohort

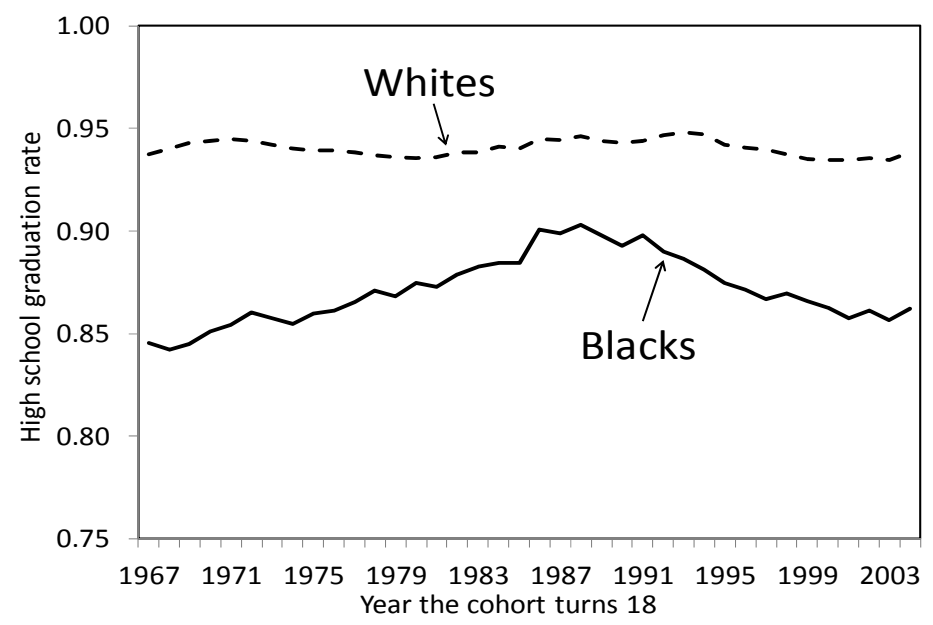

C: High School Graduation Rates, by Sex, Race and Cohort

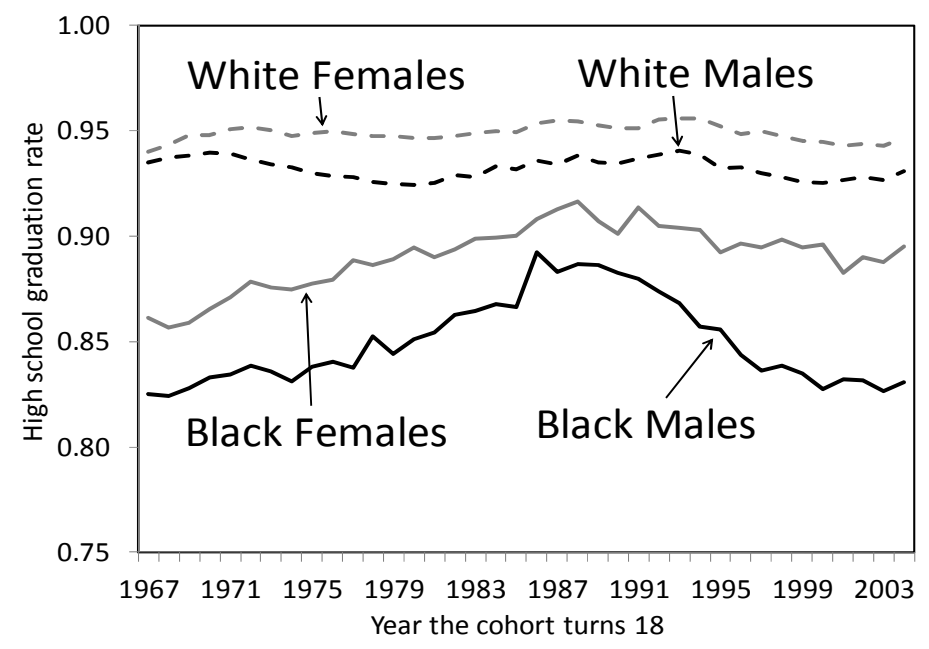

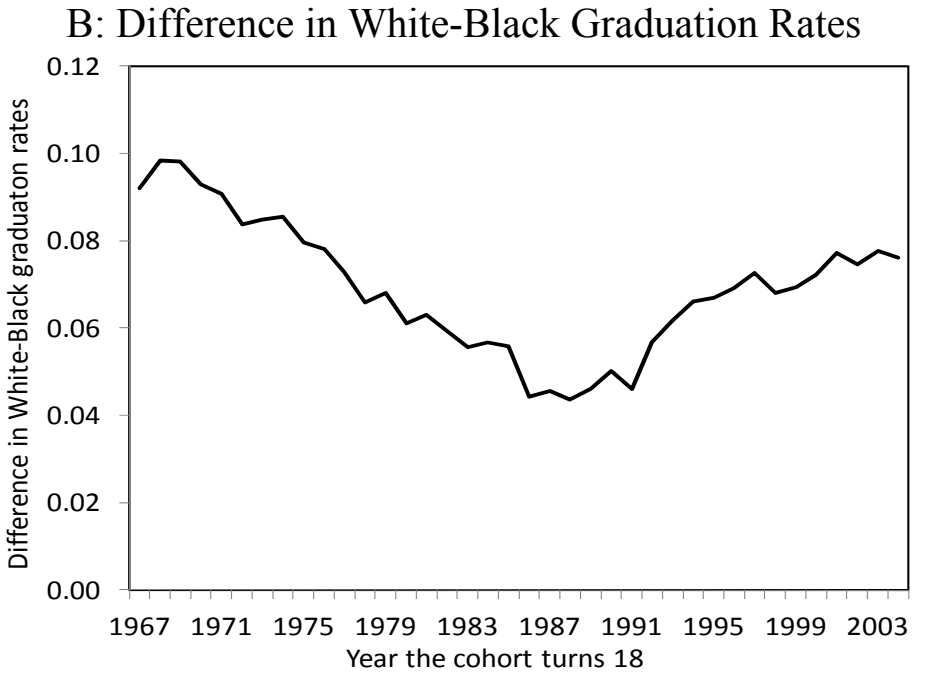

D: Differences in White-Black Graduation Rates, by Sex

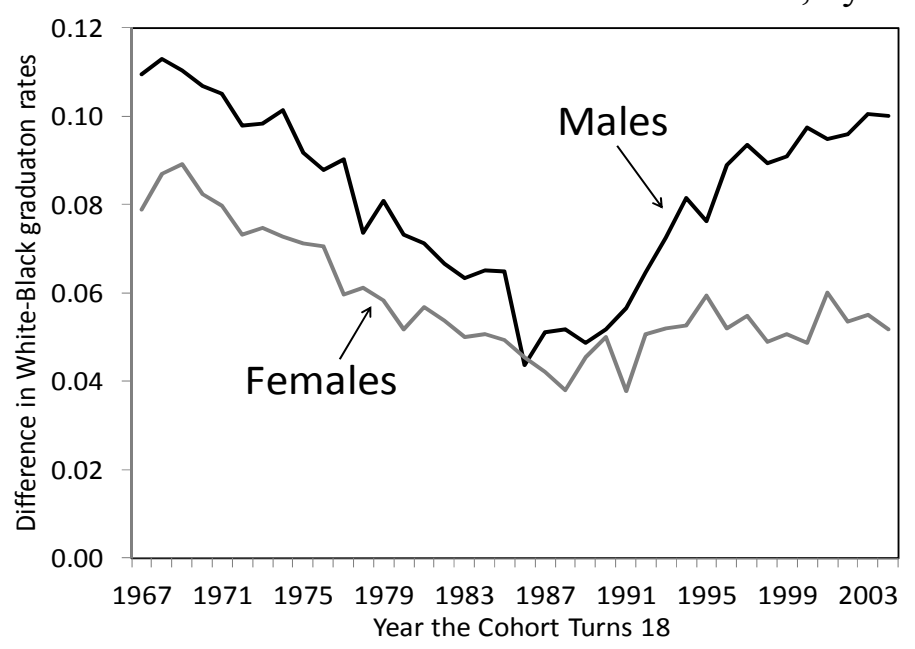


Figure 2 Expectations of Death by Age 30 for a Black Males at Age 15, Based on Contemporaneous Age-specific Mortality Rates
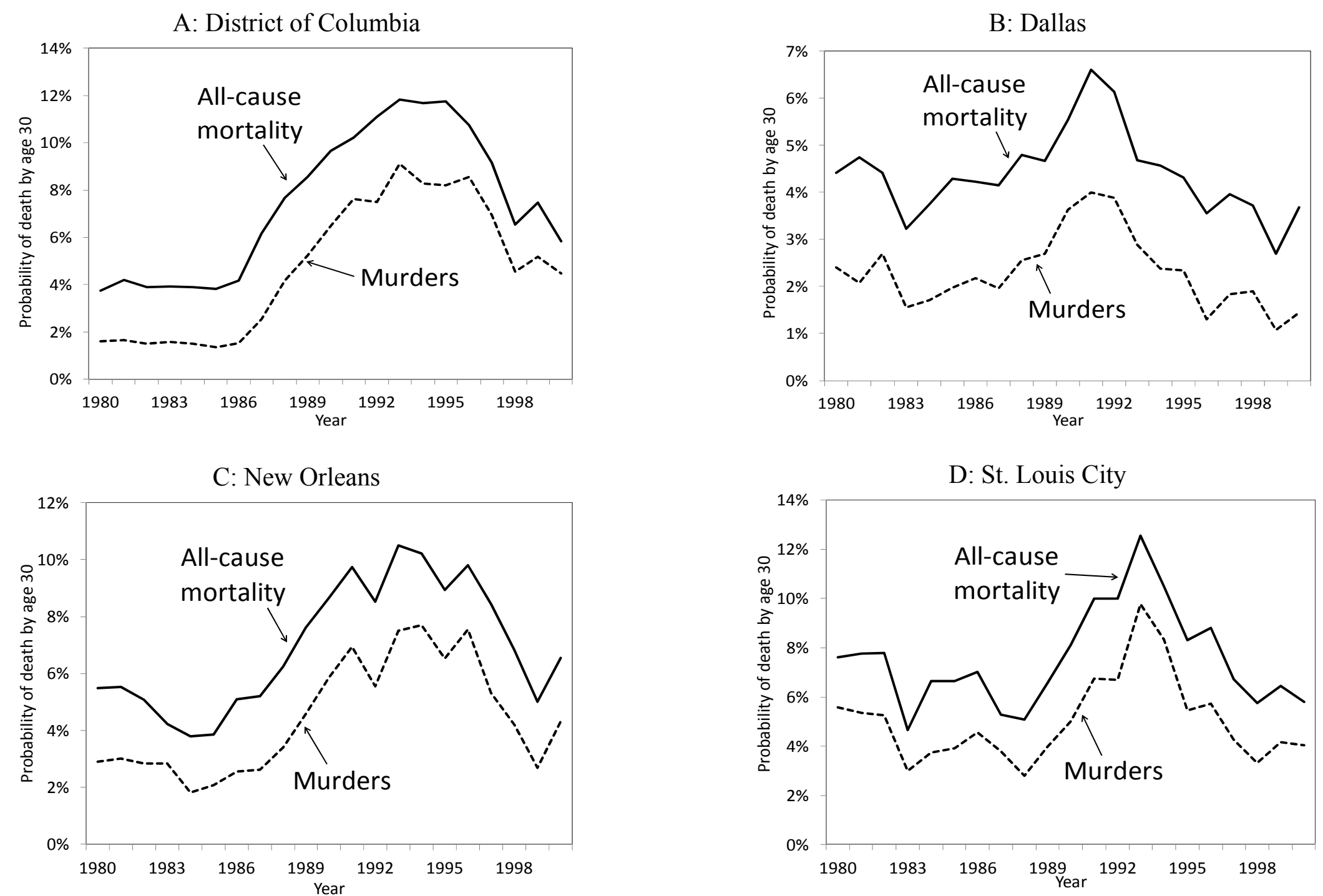
Figure 3 High School Graduation Rates by when Cohorts Turn Age 18 in Relation to When Crack Cocaine Entered MSAs and States (Based on State of Birth), by Race and Sex, 2000 Census 5\% PUMS
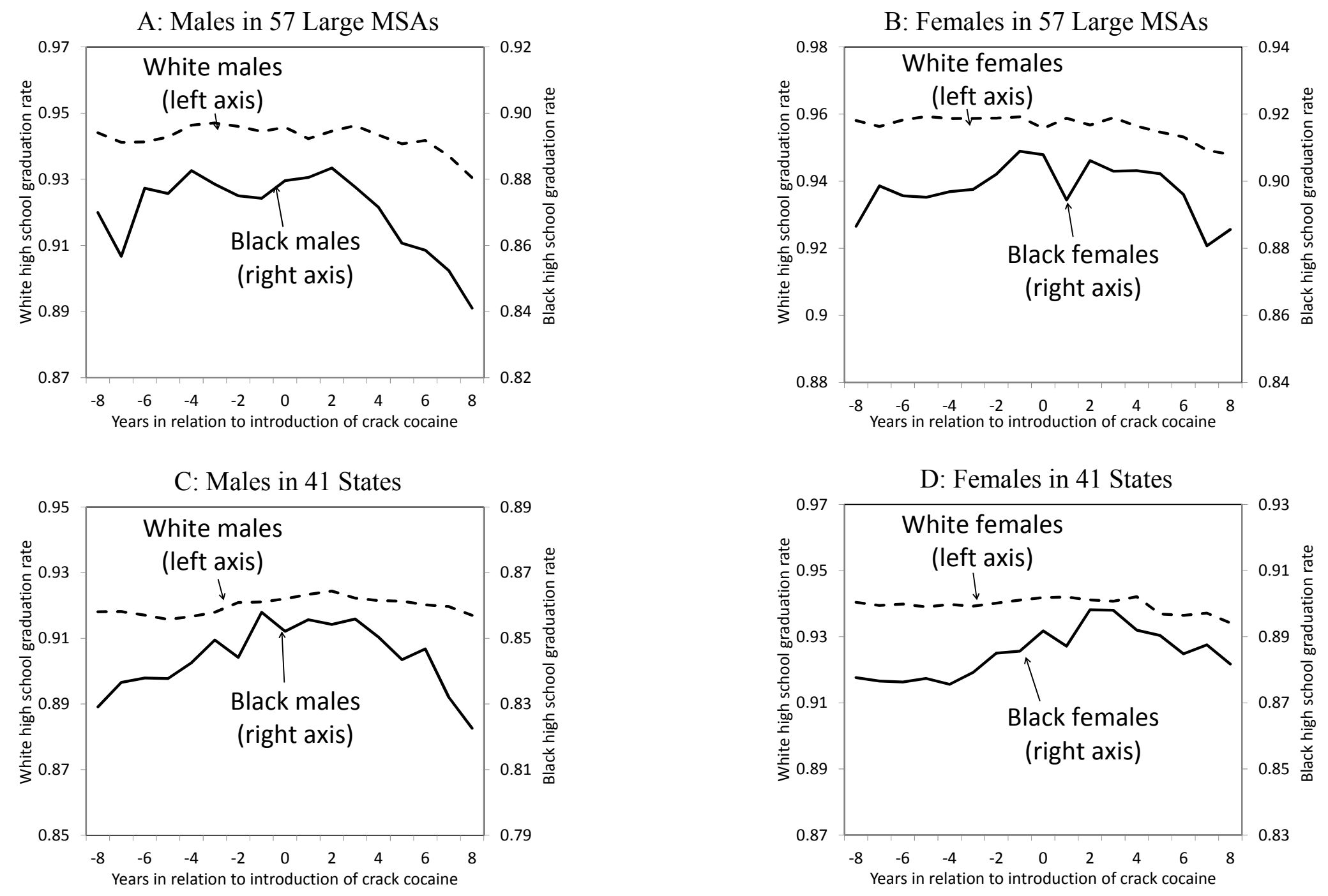
Figure 4 Murder Rates (Deaths/100,000 pop.) and Prison Intake Rates for Various Groups, 1980-2000

A: Murder Rates for Various Age Groups

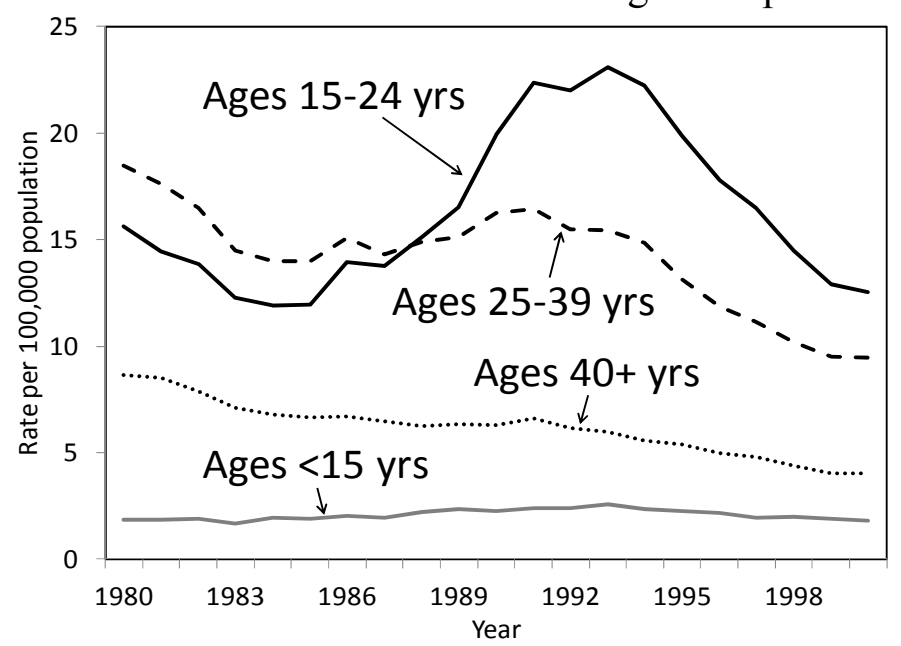

C: Change in Murder Rates of Black Males Aged 15-24, By Area Population Size

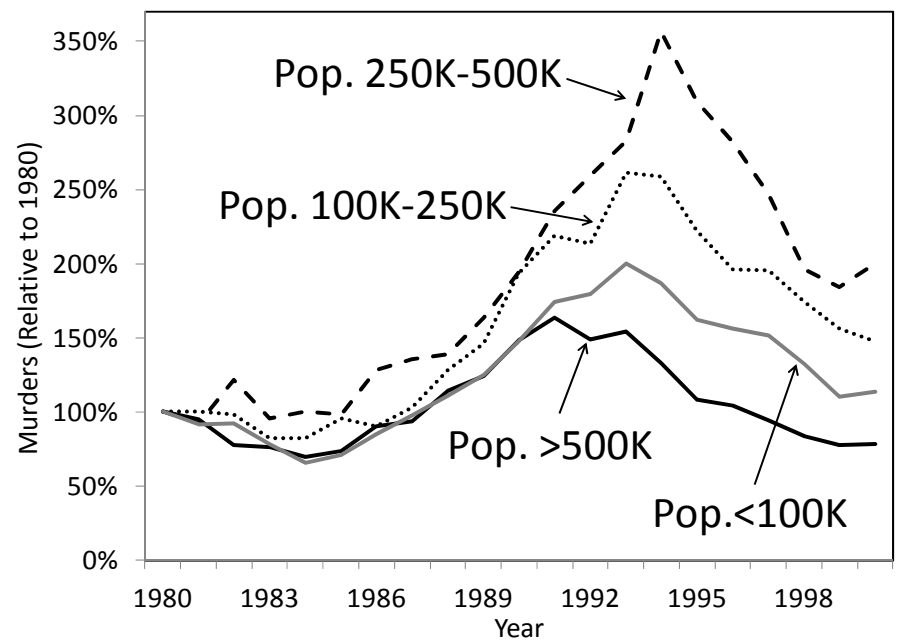

B: Murder Rate for Those Aged 15-24, By Age and Sex

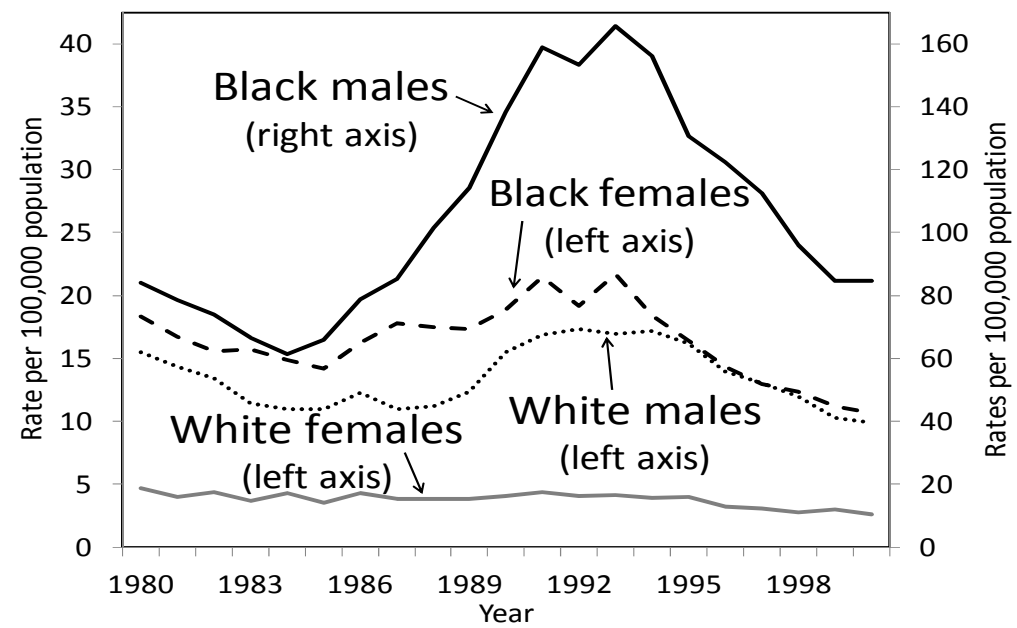

D: Prison Intake Rates for Males Aged 20-24 (17 States),

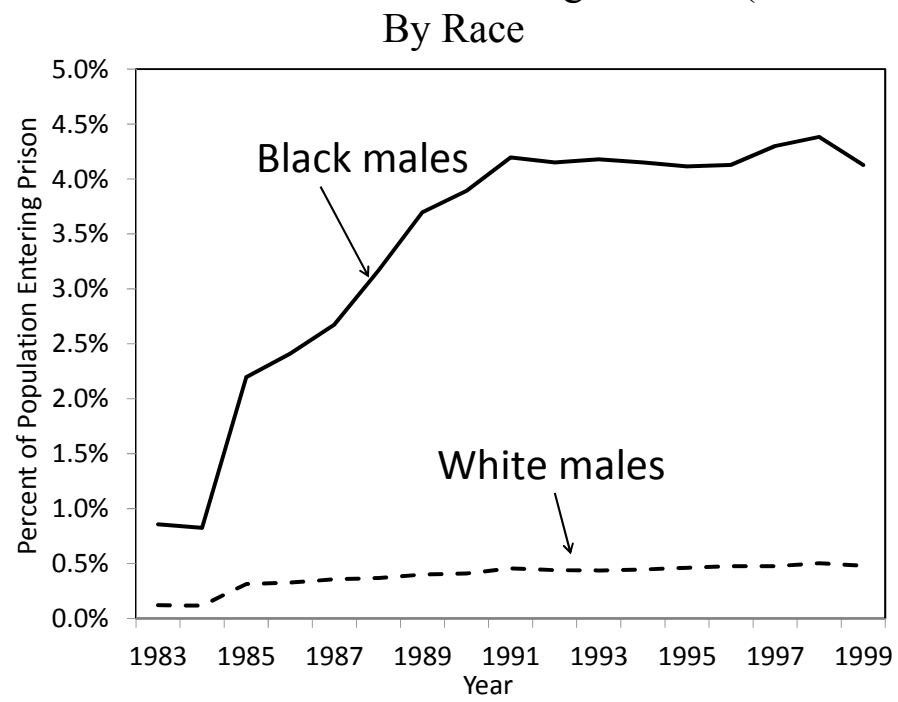


Figure 5 Murder Rates (Murders/100,000 People), Before and After the Introduction of Crack in MSAs, By Race and Sex
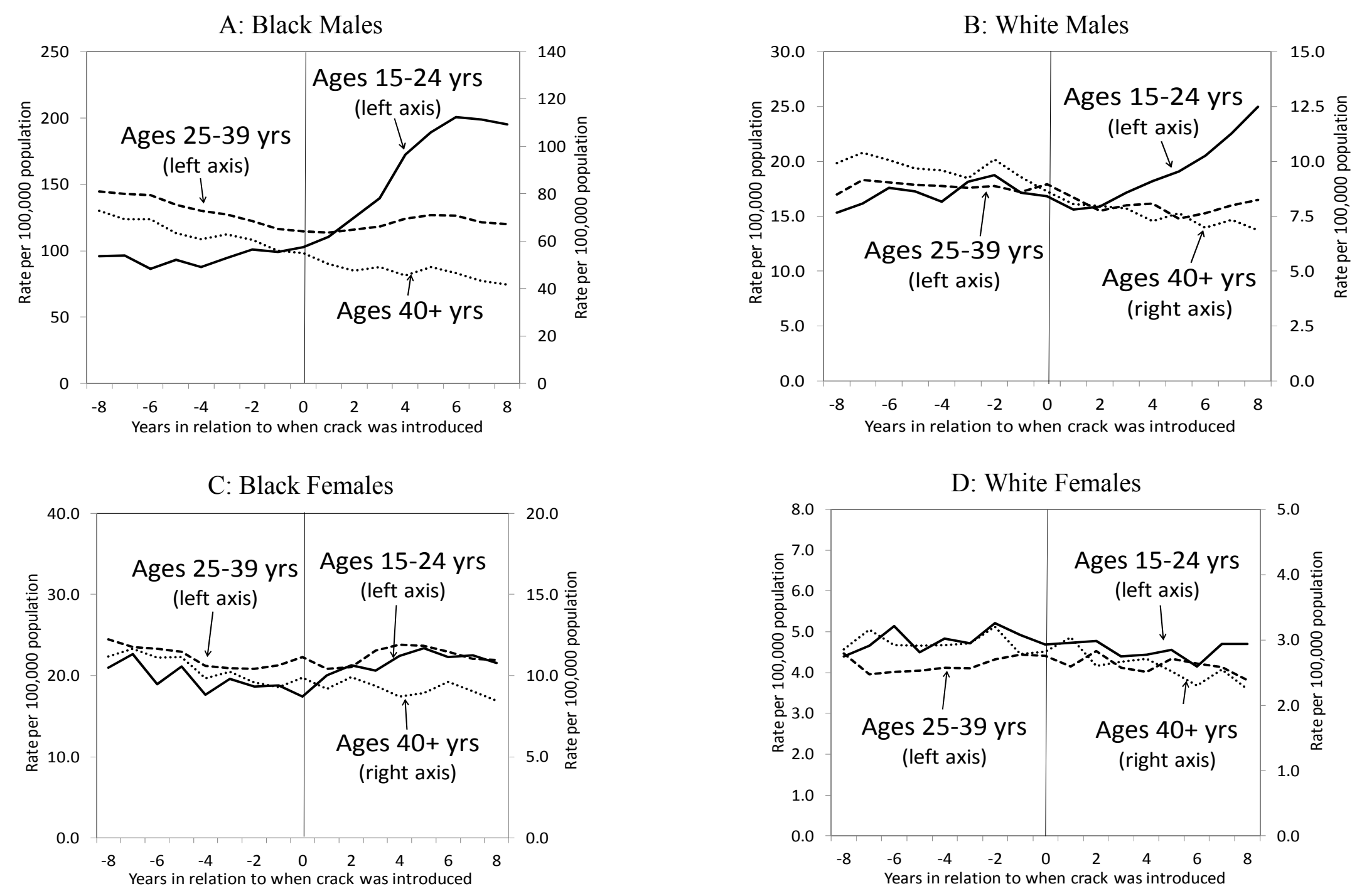
Figure 6 White/Black Test Score Gaps for 9, 13 and 17 year olds

A: Percentage Differences in White/Black NAEP-LTT Reading Scores

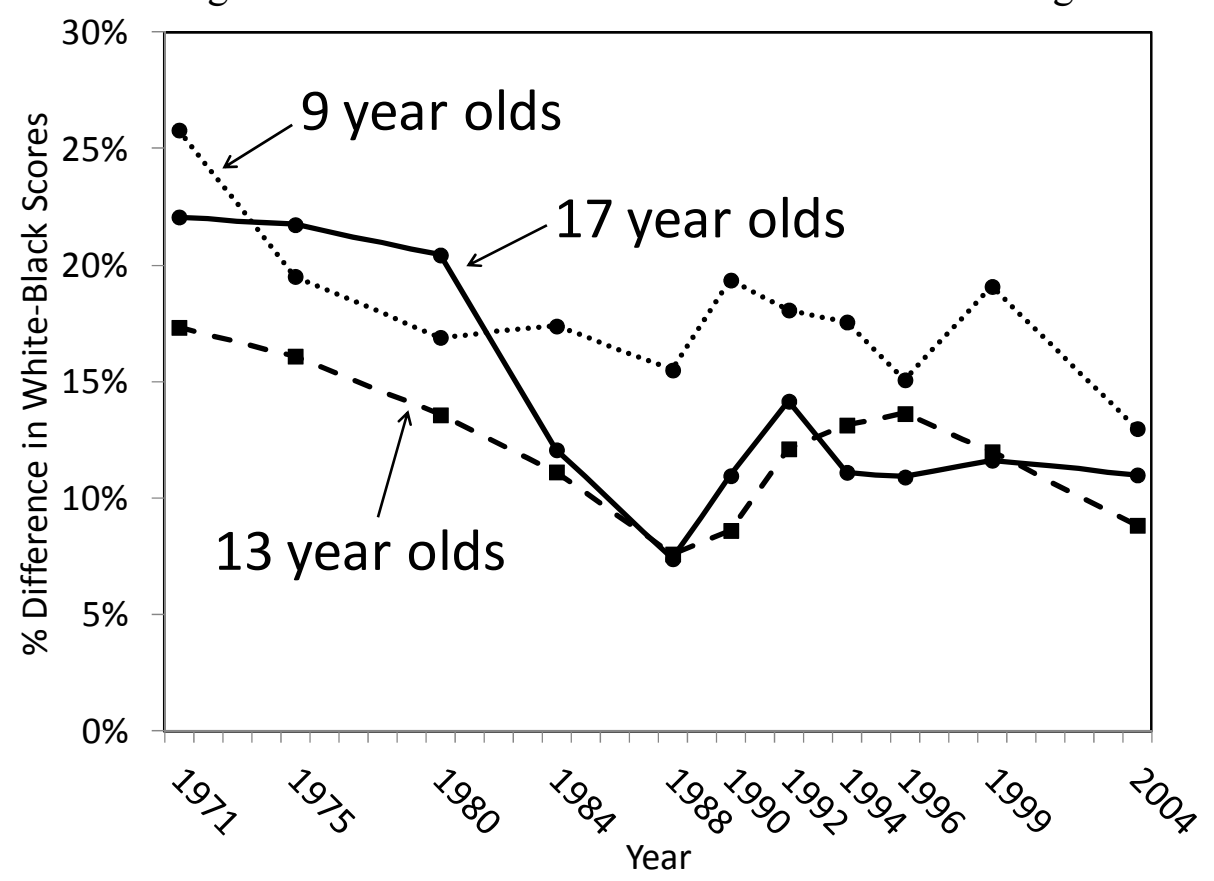

B: Percentage Differences in White/Black NAEP-LTT Math Scores

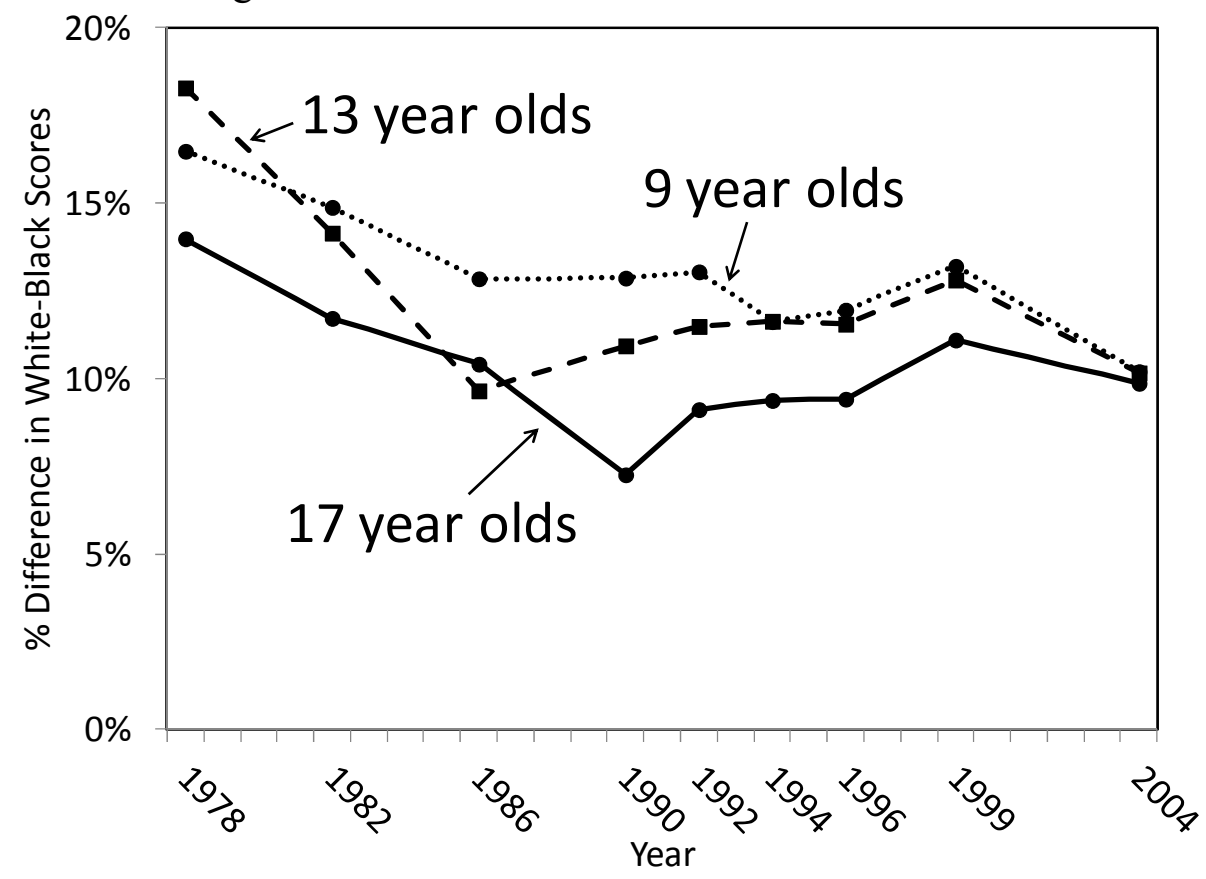


Table 1 Year Crack Arrives in the 57 Largest Metropolitan Statistical Areas (by 1980 Population), Based on Cocaine-related Deaths in Two Consecutive Years, 1981-1998

\begin{aligned} & \hline \hline Year Metropolitan Statistical Area \\ & \hline 1982 Los Angeles/Long Beach; Miami; New York \\ & 1983 Atlanta; Riverside/San Bernadino; San Francisco/Oakland \\ & 1984 Ft. Lauderdale; San Jose; Seattle/Bellevue/Everett; Tampa/St. Petersburg/Clearwater \\ & 1985 Albany/Schenectady/Troy; Dallas/Fort Worth/Arlington; Detroit; Kansas City; \\ & Philadelphia; Washington, DC \\ & 1986 Boston; Chicago; Cleveland; Indianapolis; Memphis; Minneapolis/St. Paul; Monmouth- \\ & Ocean, NJ; Newhaven/Bridgeport; New Orleans; Newark, NJ; Orange Co. CA; \\ & Sacramento \\ & Cincinnati; Greensboro/Winston Salem/High Point; Milwaukee/Waukesha Norfolk/VA \\ & Beach/Newport News; Providence \\ & Buffalo/Niagara Falls; Denver; Hartford, CT; Houston; Louisville; Nashville; Oklahoma \\ & City; Orlando; Phoenix/Mesa; Pittsburgh; Portland, OR/Vancouver, WA; Rochester; Salt \\ & Lake City/Ogden; San Diego \\ & Baltimore; Birmingham; Charlotte, NC/Gastonia, NC/Rock Hill, SC; Grand \\ & Rapids/Muskegeon/Holland, MI; St. Louis, MO \\ & 1991 Bergen/Passaic; Dayton/Springfield; Middlesex/Somerset/Hunterdon, NJ \\ & 1992 Columbus \\ & 1994 San Antonio \\ & \hline \hline\end{aligned}

The Nassua/Suffolk MSA is omitted because cocaine-related deaths were present in multiple years prior to 1981 .

Table 2 Year Crack Arrives in a State based on Cocaine-related Deaths in Two Consecutive Years, 1981-1998

\begin{aligned} & \hline \hline Year State \\ & \hline 1981 California \\ & 1982 Florida, New York \\ & 1983 Arizona, Georgia \\ & 1984 Colorado, Michigan, Missouri, Virginia, Washington \\ & 1985 District of Columbia, Illinois, Indiana, Maryland, New Mexico, Pennsylvania, South \\ & Carolina, Texas \\ & 1986 Alabama, Connecticut, Indiana, Kansas, Louisiana, Massachusetts, Minnesota, \\ & Mississippi, New Jersey, Ohio, Tennessee \\ & 1987 Arkansas, Kentucky, Nebraska, Nevada, North Carolina, Oregon, Rhode Island, West \\ & Virginia, Wisconsin \\ & \hline \hline\end{aligned}

Ten states with small black populations are omitted (HI, AK, ID, ME, MT, NH, ND, SD, VT, WY). The criterion for the three largest states (CA, NY, and TX) is two or more deaths in two consecutive years. 
Table 3 Maximum Likelihood Weibull Duration Model Estimates of the Relationship Between MSA Characteristics and When Crack Cocaine Arrives, 50 Largest MSAs

\begin{tabular}{|c|c|c|}
\hline Covariates & $\begin{array}{c}\text { Hazard Ratio } \\
\text { 1980 Levels } \\
{[95 \% \text { CI }]} \\
(1)\end{array}$ & $\begin{array}{c}\text { Hazard Ratio } \\
\text { Changes 1970-80 } \\
{[95 \% \text { CI }]} \\
(2)\end{array}$ \\
\hline $\begin{array}{l}\text { Min. Distance NY/MIA/LA } \\
\text { (per } 100 \text { miles) }\end{array}$ & $\begin{array}{c}0.908^{* *} \\
{[0.828,0.996]}\end{array}$ & $\begin{array}{c}0.919^{*} \\
{[0.831,1.015]}\end{array}$ \\
\hline Log 1980 Population & $\begin{array}{c}2.657 * * * \\
{[1.593 .4 .429]}\end{array}$ & $\begin{array}{c}2.873 * * * \\
{[1.776 .4 .648]}\end{array}$ \\
\hline$\%$ White & $\begin{array}{c}1.021 \\
{[0.975 .1 .068]}\end{array}$ & $\begin{array}{c}1.030 \\
{[0.882 .1 .204]}\end{array}$ \\
\hline$\%$ Black & $\begin{array}{c}1.012 \\
{[0.938 .1 .091]}\end{array}$ & $\begin{array}{c}1.073 \\
{[0.801 .1 .438]}\end{array}$ \\
\hline$\%$ Black Poverty & $\begin{array}{c}0.946 \\
{[0.835 .1 .072]}\end{array}$ & $\begin{array}{c}0.948 \\
{[0.873 .1 .029]}\end{array}$ \\
\hline$\%$ Black Unemployment & $\begin{array}{c}0.963 \\
{[0.848 .1 .094]}\end{array}$ & $\begin{array}{c}0.928 \\
{[0.700 .1 .230]}\end{array}$ \\
\hline \% Black HS Dropout & $\begin{array}{c}0.951 \\
{[0.798 .1 .132]}\end{array}$ & $\begin{array}{c}0.920 \\
{[0.805 .1 .051]}\end{array}$ \\
\hline$\%$ Black HS Graduate & $\begin{array}{c}0.878 \\
{[0.728 .1 .059]}\end{array}$ & $\begin{array}{c}0.892 \\
{[0.757 .1 .051]}\end{array}$ \\
\hline$\%$ Black Some College & $\begin{array}{c}0.983 \\
{[0.770 .1 .255]}\end{array}$ & $\begin{array}{c}0.875 \\
{[0.718 .1 .067]}\end{array}$ \\
\hline $\mathrm{N}$ & 50 & 50 \\
\hline
\end{tabular}


Table 4 Maximum Likelihood Estimates of Difference-in-Difference Negative Binomial Model for Murder Counts, Eight Years Before and Nine Years After Crack Arrives, 57 Large MSAs

\begin{tabular}{|c|c|c|c|c|c|}
\hline \multirow[b]{2}{*}{ Treatment Group } & \multicolumn{3}{|c|}{ In Treatment Group x } & \multirow[b]{2}{*}{$\begin{array}{c}\mathrm{p} \text {-value, } \\
\text { After } \\
\text { Coefs. }=0\end{array}$} & \multirow{2}{*}{$\begin{array}{c}\text { Mean Murder } \\
\text { Rate, Treated } \\
\text { Group, Year } \\
\text { Before Crack } \\
\text { Arrives }\end{array}$} \\
\hline & $\begin{array}{c}\text { 0-2 Years } \\
\text { After } \\
\text { Crack }\end{array}$ & $\begin{array}{c}\text { 3-5 Years } \\
\text { After } \\
\text { Crack }\end{array}$ & $\begin{array}{c}\text { 6-8 Years } \\
\text { After } \\
\text { Crack } \\
\end{array}$ & & \\
\hline \multicolumn{6}{|c|}{ Panel A: Male MSA residents } \\
\hline Black, 15-24 & $\begin{array}{c}0.252 * * * \\
(0.064)\end{array}$ & $\begin{array}{c}0.703 * * * \\
(0.082)\end{array}$ & $\begin{array}{c}1.000 * * * \\
(0.056)\end{array}$ & $<0.0001$ & 99.9 \\
\hline Black, 25-39 & $\begin{array}{c}0.062 * * \\
(0.028)\end{array}$ & $\begin{array}{c}0.198 * * * \\
(0.037)\end{array}$ & $\begin{array}{c}0.329 * * * \\
(0.060)\end{array}$ & $<0.0001$ & 118.0 \\
\hline Whites, 15-24 & $\begin{array}{c}0.042 \\
(0.050)\end{array}$ & $\begin{array}{c}0.185^{* * *} * \\
(0.054)\end{array}$ & $\begin{array}{c}0.491 * * * \\
(0.029)\end{array}$ & $<0.0001$ & 17.9 \\
\hline Whites, 25-39 & $\begin{array}{c}0.119 * * * \\
(0.024)\end{array}$ & $\begin{array}{c}0.075 * * * \\
(0.024)\end{array}$ & $\begin{array}{c}0.152 * * * \\
(0.029)\end{array}$ & $<0.0001$ & 17.8 \\
\hline \multicolumn{6}{|c|}{ Panel B: Female MSA residents } \\
\hline Blacks, 15-24 & $\begin{array}{c}0.030 \\
(0.058)\end{array}$ & $\begin{array}{c}0.103 \\
(0.068)\end{array}$ & $\begin{array}{c}0.216^{* * *} \\
(0.057)\end{array}$ & $<0.0001$ & 19.0 \\
\hline Blacks, 25-39 & $\begin{array}{c}-0.003 \\
(0.047)\end{array}$ & $\begin{array}{c}0.053 \\
(0.048)\end{array}$ & $\begin{array}{c}0.114 * * * \\
(0.035)\end{array}$ & 0.0058 & 21.4 \\
\hline Whites, 15-24 & $\begin{array}{l}-0.017 \\
(0.064)\end{array}$ & $\begin{array}{l}-0.023 \\
(0.068)\end{array}$ & $\begin{array}{c}0.181 * * * \\
(0.064)\end{array}$ & 0.012 & 5.1 \\
\hline Whites, 25-39 & $\begin{array}{c}0.116^{* *} \\
(0.048)\end{array}$ & $\begin{array}{c}0.149 * * \\
(0.050)\end{array}$ & $\begin{array}{c}0.209 * * * \\
(0.045)\end{array}$ & $<0.0001$ & 4.2 \\
\hline
\end{tabular}

$* \mathrm{p}<0.10, * * \mathrm{p}<0.05, * * * \mathrm{p}<0.01$

Standard errors in parentheses allow for arbitrary correlation in observations within an MSA over time. Each model has 1,938 observations -2 groups x 17 years x 57 cities. The comparison group in each model is residents in the same race/sex cell that are aged over 40. Observations are weighted by the population within each cell. Other covariates include a dummy variable for the comparison sample, MSA fixed effects, year fixed effects, and MSA-specific time trends. 
Table 5 Linear Probability Estimates of High School Graduation Models, Cohorts that Turned 18 1976-1999

\begin{tabular}{|c|c|c|c|c|c|c|}
\hline & & & \multicolumn{4}{|c|}{41 States } \\
\hline & \multicolumn{2}{|c|}{57 MSAs } & \multicolumn{2}{|c|}{ State of Residence } & \multicolumn{2}{|c|}{ State of Birth } \\
\hline & $\begin{array}{l}\text { Males } \\
\text { (1) }\end{array}$ & $\begin{array}{l}\text { Females } \\
\text { (2) }\end{array}$ & $\begin{array}{l}\text { Males } \\
\text { (3) }\end{array}$ & $\begin{array}{l}\text { Females } \\
\text { (4) }\end{array}$ & $\begin{array}{l}\text { Males } \\
(5)\end{array}$ & $\begin{array}{c}\text { Females } \\
(6)\end{array}$ \\
\hline \multicolumn{7}{|l|}{ Panel A: Model (1) } \\
\hline Black*Pre-Crack Time Trend & $\begin{array}{c}0.0017 * * * \\
(0.0004)\end{array}$ & $\begin{array}{c}0.0013 \\
(0.0004)\end{array}$ & $\begin{array}{c}0.0035 * * * \\
(0.0007)\end{array}$ & $\begin{array}{c}0.0023 * * * \\
(0.0004)\end{array}$ & $\begin{array}{c}0.0033 * * * \\
(0.0006)\end{array}$ & $\begin{array}{l}0.002 * * * \\
(0.0004)\end{array}$ \\
\hline Black* (Years after crack $\geq 0$ ) & $\begin{array}{c}-0.0029 * * \\
(0.0009)\end{array}$ & $\begin{array}{l}-0.001 * \\
(0.0006)\end{array}$ & $\begin{array}{c}-0.0034 * * * \\
(0.0007)\end{array}$ & $\begin{array}{l}-0.00003 \\
(0.0004)\end{array}$ & $\begin{array}{c}-0.0034 \\
(0.0006)\end{array}$ & $\begin{array}{l}-0.0002 \\
(0.0004)\end{array}$ \\
\hline $\mathrm{R}^{2}$ & 0.0216 & 0.0182 & 0.0226 & 0.0162 & 0.0209 & 0.0154 \\
\hline \multicolumn{7}{|l|}{ Panel B: Model (2) } \\
\hline Black*Pre-Crack Time Trend & $\begin{array}{c}0.0015 * * \\
(0.0005)\end{array}$ & $\begin{array}{l}0.0012 * * \\
(0.0004)\end{array}$ & $\begin{array}{c}0.0036 * * * \\
(0.0007)\end{array}$ & $\begin{array}{l}0.002 * * * \\
(0.0004)\end{array}$ & $\begin{array}{c}0.0032 * * * \\
(0.0006)\end{array}$ & $\begin{array}{c}0.0016 * * * \\
(0.0005)\end{array}$ \\
\hline Black $* 1($ Years after $\operatorname{crack}=0)$ & $\begin{array}{l}-0.0023 \\
(0.0055)\end{array}$ & $\begin{array}{c}0.0036 \\
(0.0032)\end{array}$ & $\begin{array}{l}-0.0070 \\
(0.0051)\end{array}$ & $\begin{array}{c}0.005^{*} \\
(0.0027)\end{array}$ & $\begin{array}{l}-0.0039 \\
(0.0038)\end{array}$ & $\begin{array}{c}0.0073 * * \\
(0.0027)\end{array}$ \\
\hline Black $* 1($ Years after $\operatorname{crack}=1)$ & $\begin{array}{l}-0.0003 \\
(0.0048)\end{array}$ & $\begin{array}{l}-0.0085^{*} \\
(0.0043)\end{array}$ & $\begin{array}{l}-0.0031 \\
(0.0049)\end{array}$ & $\begin{array}{c}0.0003 \\
(0.0036)\end{array}$ & $\begin{array}{l}-0.0040 \\
(0.0049)\end{array}$ & $\begin{array}{c}0.0023 \\
(0.0031)\end{array}$ \\
\hline Black $* 1($ Years after crack $=2)$ & $\begin{array}{c}0.0014 \\
(0.0052)\end{array}$ & $\begin{array}{c}0.0025 \\
(0.0045)\end{array}$ & $\begin{array}{l}-0.0065 \\
(0.0043)\end{array}$ & $\begin{array}{l}0.01 * * \\
(0.003)\end{array}$ & $\begin{array}{c}-0.0082 * * \\
(0.0034)\end{array}$ & $\begin{array}{l}0.0086 * * \\
(0.0028)\end{array}$ \\
\hline Black $* 1($ Years after $\operatorname{crack}=3)$ & $\begin{array}{l}-0.0030 \\
(0.0061)\end{array}$ & $\begin{array}{c}0.0004 \\
(0.0038)\end{array}$ & $\begin{array}{l}-0.0054 \\
(0.0055)\end{array}$ & $\begin{array}{c}0.0093 * * \\
(0.004)\end{array}$ & $\begin{array}{l}-0.0036 \\
(0.0060)\end{array}$ & $\begin{array}{l}0.0062 * \\
(0.0036)\end{array}$ \\
\hline Black $* 1($ Years after $\operatorname{crack}=4)$ & $\begin{array}{l}-0.0077 \\
(0.0058)\end{array}$ & $\begin{array}{c}0.0004 \\
(0.0038)\end{array}$ & $\begin{array}{c}-0.0107 * * \\
(0.0051)\end{array}$ & $\begin{array}{c}0.004 \\
(0.0034)\end{array}$ & $\begin{array}{c}-0.0146 * * \\
(0.0051)\end{array}$ & $\begin{array}{c}0.0052 \\
(0.0003)\end{array}$ \\
\hline Black $* 1($ Years after crack $=5)$ & $\begin{array}{c}-0.0167 * * \\
(0.0071)\end{array}$ & $\begin{array}{c}0.0022 \\
(0.0053)\end{array}$ & $\begin{array}{c}-0.0168 * * \\
(0.0051)\end{array}$ & $\begin{array}{c}0.0044 \\
(0.0037)\end{array}$ & $\begin{array}{c}-0.0127 * * \\
(0.0050)\end{array}$ & $\begin{array}{c}0.0048 \\
(0.0031)\end{array}$ \\
\hline Black $* 1($ Years after $\operatorname{crack}=6)$ & $\begin{array}{l}-0.0157^{*} \\
(0.0081)\end{array}$ & $\begin{array}{l}-0.0023 \\
(0.0050)\end{array}$ & $\begin{array}{l}-0.0119^{*} \\
(0.0063)\end{array}$ & $\begin{array}{l}-0.0002 \\
(0.0038)\end{array}$ & $\begin{array}{c}-0.0142 * * \\
(0.0070)\end{array}$ & $\begin{array}{l}-0.0016 \\
(0.0030)\end{array}$ \\
\hline Black $* 1($ Years after crack $=7)$ & $\begin{array}{c}-0.0191 * * \\
(0.0089)\end{array}$ & $\begin{array}{c}-0.0157 * * * \\
(0.0044)\end{array}$ & $\begin{array}{c}-0.0263 * * \\
(0.0077)\end{array}$ & $\begin{array}{c}0.0026 \\
(0.0041)\end{array}$ & $\begin{array}{c}-0.0266 * * * \\
(0.0060)\end{array}$ & $\begin{array}{c}0.0028 \\
(0.0048)\end{array}$ \\
\hline Black $* 1($ Years after crack $=8)$ & $\begin{array}{c}-0.0242 * * \\
(0.0080)\end{array}$ & $\begin{array}{l}-0.0076 \\
(0.0068)\end{array}$ & $\begin{array}{c}-0.0346 * * * \\
(0.0049)\end{array}$ & $\begin{array}{l}-0.0013 \\
(0.0053)\end{array}$ & $\begin{array}{c}-0.0343 * * * \\
(0.0055)\end{array}$ & $\begin{array}{l}-0.0035 \\
(0.0049)\end{array}$ \\
\hline $\mathrm{R}^{2}$ & 0.0216 & 0.0182 & 0.0226 & 0.0162 & 0.0209 & 0.0154 \\
\hline Observations & 680,646 & 715,412 & $1,562,768$ & $1,617,620$ & $1,546,829$ & $1,618,842$ \\
\hline $\begin{array}{l}\text { Mean of dep. var. for blacks } \\
\text { the year before crack arrives }\end{array}$ & 0.879 & 0.908 & 0.856 & 0.884 & 0.858 & 0.886 \\
\hline
\end{tabular}

$* \mathrm{p}<0.10, * * \mathrm{p}<0.05, * * * \mathrm{p}<0.001$

Standard errors allow for arbitrary correlation in errors within geographic region (state or MSA). All models include cohort and geographic fixed effects, plus a dummy variable for race. 
Table 6 OLS Estimates of Impact of Crack Intensity on High School Graduation, 1976-99 Cohorts

\begin{tabular}{|c|c|c|c|c|c|c|}
\hline & \multicolumn{6}{|c|}{ Sample 1: Current MSA Residents } \\
\hline & \multicolumn{2}{|c|}{ Both Sexes, 20-24 } & \multicolumn{2}{|c|}{ Males, 20-24 } & \multicolumn{2}{|c|}{ Females, 20-24 } \\
\hline & $\begin{array}{l}57 \text { MSA } \\
\text { Sample }\end{array}$ & $\begin{array}{c}174 \text { Largest } \\
\text { MSAs }\end{array}$ & $\begin{array}{l}57 \text { MSA } \\
\text { Sample }\end{array}$ & $\begin{array}{c}\text { 174 Largest } \\
\text { MSAs }\end{array}$ & $\begin{array}{l}57 \text { MSA } \\
\text { Sample }\end{array}$ & $\begin{array}{c}\text { 174 Largest } \\
\text { MSAs }\end{array}$ \\
\hline $\begin{array}{l}\text { Sex/race specific } \\
\text { murder rate during } \\
\text { HS (x 1000) }\end{array}$ & $\begin{array}{c}-0.0865 * * \\
(0.0401) \\
{[-0.005]}\end{array}$ & $\begin{array}{c}-0.1039 * * \\
(0.0322) \\
{[-0.006]}\end{array}$ & $\begin{array}{l}-0.084 * * \\
(0.0392) \\
{[-0.009]}\end{array}$ & $\begin{array}{c}-0.1075 * * * \\
(0.0326) \\
{[-0.012]}\end{array}$ & $\begin{array}{c}0.207 * * \\
(0.0935) \\
{[0.001]}\end{array}$ & $\begin{array}{l}0.1276 * \\
(0.0649) \\
{[0.0006]}\end{array}$ \\
\hline $\begin{array}{l}\mathrm{R}^{2} \\
\text { Observations }\end{array}$ & $\begin{array}{c}0.0273 \\
1,492,069\end{array}$ & $\begin{array}{c}0.0288 \\
2,165,577\end{array}$ & $\begin{array}{c}0.03 \\
728,417\end{array}$ & $\begin{array}{c}0.0323 \\
1,060,253\end{array}$ & $\begin{array}{c}0.022 \\
763,652\end{array}$ & $\begin{array}{c}0.0223 \\
1,105,324\end{array}$ \\
\hline \multirow{3}{*}{ Observations } & \multicolumn{6}{|c|}{ Sample 2: State Residents } \\
\hline & Both Se & es, 20-24 & Males & $20-24$ & Female & s, 20-24 \\
\hline & $\begin{array}{c}\text { State of } \\
\text { Birth }\end{array}$ & $\begin{array}{c}\text { State of } \\
\text { Residence }\end{array}$ & $\begin{array}{c}\text { State of } \\
\text { Birth }\end{array}$ & $\begin{array}{c}\text { State of } \\
\text { Residence }\end{array}$ & $\begin{array}{c}\text { State of } \\
\text { Birth }\end{array}$ & $\begin{array}{c}\text { State of } \\
\text { Residence }\end{array}$ \\
\hline $\begin{array}{l}\text { Sex/race specific } \\
\text { murder rate during } \\
\text { HS (x 1000) }\end{array}$ & $\begin{array}{c}-0.1819 * * \\
(0.0685) \\
{[-0.009]}\end{array}$ & $\begin{array}{c}-0.1829 * * \\
(0.0658) \\
{[-0.009]}\end{array}$ & $\begin{array}{c}-0.1947 * * \\
(0.0745) \\
{[-0.019]}\end{array}$ & $\begin{array}{c}-0.2007 * * \\
(0.0694) \\
{[-0.020]}\end{array}$ & $\begin{array}{c}0.4792 * * * \\
(0.1504) \\
{[0.002]}\end{array}$ & $\begin{array}{c}0.5415 * * * \\
(0.1478) \\
{[0.003]}\end{array}$ \\
\hline $\begin{array}{l}\mathrm{R}^{2} \\
\text { Observations }\end{array}$ & $\begin{array}{c}0.023 \\
3,631,651\end{array}$ & $\begin{array}{c}0.024 \\
3,633,645\end{array}$ & $\begin{array}{c}0.026 \\
1,792,256\end{array}$ & $\begin{array}{c}0.027 \\
1,792,612\end{array}$ & $\begin{array}{c}0.016 \\
1,839,395\end{array}$ & $\begin{array}{c}0.017 \\
1,841,033\end{array}$ \\
\hline
\end{tabular}

$* \mathrm{p}<0.10, * * \mathrm{p}<0.05, * * * \mathrm{p}<0.01$

Standard errors are in parentheses, and allow for arbitrary correlation in errors within a state/MSA.

The square brackets contain the total estimated effect of the change in the black murder rate on graduation rates between 1983 and 1993 (e.g., the value of 0.005 in the top panel of the first column represents a 0.5 percent decrease in graduation). Each model contains fixed effects for a full set of FIPS x sex x race interactions, and for cohort.

Table 7 OLS Estimates of the Impact of Crack Intensity on the High School Graduation, Based on the Separate Impacts of Murder and Prison

\begin{tabular}{lccc}
\hline \hline & $(1)$ & $(2)$ & $(3)$ \\
\hline Race-specific murder rate during HS & & $-0.246^{* *}$ & $-0.130^{* *}$ \\
(x 1000) & & $(0.078)$ & $(0.060)$ \\
& & {$[-0.025]$} & {$[-0.013]$} \\
Race-specific prison intake rate & $-1.017^{* * *}$ & & $-0.777^{* *}$ \\
(x 1000) & $(0.258)$ & & $(0.264)$ \\
& {$[-0.030]$} & & {$[-0.023]$} \\
$\mathrm{R}^{2}$ & 0.029 & 0.029 & 0.029 \\
Observations & 931,151 & 931,151 & 931,151 \\
\hline \hline
\end{tabular}

$* \mathrm{p}<0.10, * * \mathrm{p}<0.05, * * * \mathrm{p}<0.01$

Each column has 931,151 observations. Standard errors are in parentheses, and allow for arbitrary correlation in errors within a state. The square brackets contain the estimated total effects that changes in the murder and incarceration rates between 1983 and 1993 had on black graduation rates. Each model contains fixed effects for a full set of FIPS x sex x race interactions, and for cohort effects. 


\title{
Web Appendix: \\ “The White/Black Educational Gap, Stalled Progress, and the Long Term Consequences of the Emergence of Crack Cocaine Markets”
}

\author{
William N. Evans, Craig Garthwaite, and Timothy J. Moore
}

\section{Contents}

I. Identifying the Arrival of Crack Cocaine Markets

II. Adding Time-varying Socioeconomic Characteristics to Reduced-form Regression

III. Results using Murder and Incarceration in a Sample of Consistent States

IV. Adding Emergency Department Data as a Measure of Crack Intensity

\section{Identifying the Arrival of Crack Cocaine Markets}

We use the National Center for Health Statistics' Multiple Cause of Death (MCOD) data files to identify cocaine-related deaths. They contain a unique record of each death in the United States, including information about the decedent's age, race, gender, place of residence, and cause of death. The public-use files are available for download from the National Bureau of Economic Research. We define a cocaine-related death as any case where cocaine dependence or use is listed any of the 18 potential causes of death. We use the relevant International Classification of Disease codes for cocaine dependence and cocaine abuse, which between 1979 and 1998 are ICD-9 codes 304.2 (Cocaine dependence) and 305.6 (Cocaine abuse). As discussed in the paper, cocaine-related deaths were rare prior to 1982 and then increased throughout the 1980s and 1990s. We provide details on the main measure we construct for large MSAs and in states with large black populations.

\section{Crack Arrival in Metropolitan Statistical Areas (MSAs)}

The level of geographic detail varies considerably in the MCOD data with less detail provided in more recent years. We are able to consistently define 174 MSAs over the 1980 to 1998 period. We define the arrival of crack as the first of two consecutive years where cocaine-related deaths occurred. We do this for the 58 largest MSAs in terms of their 1980 populations, which is every MSA with more than 800,000 people in 1980. The measure is quite noisy in cities with 1980 populations below 800,000 . Nassua/Suffolk is omitted as there are consecutive years of cocaine-related deaths occurring prior to the arrival of crack cocaine in the United States. These cocaine deaths are likely driven by 
individuals with severe additions to powder cocaine; treatment for cocaine addiction is documented in Nassua/Suffolk in the 1970s (Copemann and Shaw, 1975).

Our estimates of when crack cocaine arrives in particular cities are presented in Column 1 of Table A1. Our dates are generally within a year of the earliest dates given in newspaper reports and ethnographies for larger cities. Our date for Los Angeles is 1982, compared to 1981 in the Los Angeles Times and 1983 in a Newsweek article. Our date for New York is 1982, the same year as Johnson, Golub and Fagan (1995) report crack use and one year earlier than reports cited in Agar (2003). Our date for Detroit is 1985, one year later than in a report by Adler (1995). A Kansas City police taskforce targeting a crack distributor was set up in 1986, one year after our date. The Washington Post first covers crack's arrival in that city in 1986, while we date its arrival in 1985. These news reports suggest that our dating measure is generally consistent with contemporaneous accounts. The dates also generally match those in Cooper (1998) who gathered information from law enforcement reports.

The dates in the first column of the table are not sensitive to alternative definitions of when crack arrives. In the next two columns, we consider two alternate definitions. The first one is the first year of a three-year period where cocaine-related deaths are reported in at least two of the years (in Column 2), while the other is the first of three consecutive years with cocaine-related deaths (in Column 3). The two measures are generally consistent with the main measure. Of the dates assigned under the "two consecutive years" rule, 44 of 57 are consistent with the "two years in a three year period" rule and 44 of 57 are consistent with the "three consecutive years" rule. Results using the alternate MSA dates are similar to the results presented in the paper; these are available on request.

The only city where our preferred measure misses the arrival of crack by more than that is Baltimore. We place the arrival of crack there in 1989. In contrast, media reports in the Baltimore City Paper and the New York Times discuss the presence of Baltimore crack markets in 1984 and 1987 respectively. Under an alternate measure discussed below, where cocaine-related deaths are reported in at least two of three consecutive years, crack cocaine is estimated to arrive in Baltimore in 1985.

Grogger and Willis (2000) report two different dates for when crack arrived in a smaller list of large cities. The dates are also presented in Table A1. Grogger and Willis sent surveys to police chiefs in 1991 and asked them, among other things, when they first became aware of the existence of crack. They receive responses from police chiefs in 25 cities, and these data are presented in Column 
4. They also used data from the Drug Abuse Warning Network (DAWN) in 22 cities, a surveillance system that monitors drug-related visits to hospital emergency departments, and identify when there is a sharp increase of cases where the patient reports smoking cocaine (which is rare before crack cocaine). These are presented in Column 5. The correlation between our measure and police chief reports is 0.43 , and between our measure and the DAWN measure is 0.37 . These are reasonably high, particularly given that the correlation across Grogger and Willis' two measures is 0.32 . In the paper, we discuss results using dates from the survey of police chiefs conducted by Grogger and Willis. Results are similar using their DAWN-derived dates; these are available on request.

\section{Crack Arrival in States}

A similar approach is taken for timing the arrival of crack cocaine in 40 states (and the District of Columbia). The main measure is again two consecutive years where cocaine-related deaths are reported in a location. Some states have large populations, however, so for states with more than 12 million people in 1980 the arrival is based on two or more cocaine-related deaths two years in a row (these states are: CA, NY, and TX). Washington DC MSA dates are used for the District of Columbia. Using these measures, there are no states that would have been defined as crack arriving in 1980. The early crack arrival dates are 1981 for California and 1982 for Florida and New York. The dates are more compressed in this analysis, with all 41 states having crack cocaine by 1988 .

Table 5 shows these main crack arrival dates (in Column 1), along with dates based on the first year of a three-year period where cocaine-related deaths are reported in at least two of the years (in Column 2) and the first of three consecutive years with cocaine-related deaths (in Column 3). Comparing the main measure and the "two of three years" measure, the dates are the same in 29 of the states, with the timing being two years earlier in seven states. Comparing the main measure to the second alternate measure of "three consecutive years," the arrival of crack cocaine is the same in 39 of the 41 states.

\section{Adding Time-Varying Socioeconomic Characteristics to Reduced-Form Regressions}

In these additional results, time-varying economic and community characteristics are added to the analysis of the reduced-form relationship between crack arrival dates and high school graduation rates. As discussed in the paper, we estimated a specification of equation (1) that includes covariates that vary by state, race and year, such as the educational status of mothers, the percentage of children 
without a father present in the home, median family income, and the state unemployment rate. The first three variables were calculated from the Annual Demographic file from the March Current, Population Survey (CPS) while the state unemployment rate is calculated from all monthly CPS samples. These additional variables are available from 1978. We also include race-specific measures of the school environment averaged to the state level including current expenditures per student, the racial fractionalization of the school, and the within-district Gini coefficient in family income. These variables are calculated from the data in Corcoran and Evans (2010) which is a panel data set of unified school districts from 1970/1980/1990/2000. To get race-specific state level averages, we aggregate data from the district to the state level using the number of whites and blacks in the district as the weight. We interpolate data between census dates.

Three versions of equation (1) are separately estimated for males and females. The first is a repetition of the main regression presented in the paper. The second is one where the years are restricted to between 1978 and 1999, which are the years for which we have all of the additional variables. The third uses the same sample as for the second regression, with all of the additional covariates. These are presented in Table A3, with the results for males in columns (1) to (3), and the results for females in columns (4) to (6).

\section{Results Using Murder and Incarceration Rates in a Consistent Sample of States}

Table 7 in the paper reports estimates from a regression of male graduation rates on the racespecific Bureau of Justice Statistics National Corrections Reporting Program (NCRP) prison intake rate of 20 to 24 year olds when a respondent turned 18. The sample we use includes all of the stateyear observations for which incarceration data is available. Here, we present results for the 15 states that provided incarceration data to the NCRP every year from 1983 to 1999 . There are 17 states that report in all years but New Hampshire and North Dakota are not part of the 41 state sample, so we report results using a sample of 15 states.

The regression also includes race-specific state fixed effects, and cohort fixed effects. The first panel of Table A4 reproduces from Table 7 in the paper estimates from the full sample of states reporting NCRP prison intake data in any year. The first column shows the results with only incarceration rates as a continuous covariate, the second column shows results using only the murder rate in a similar way, and the third column shows the independent impacts of murder and prison rates when they are in the same regression. The second panel shows the same set of results for the 15 state 
sample.

\section{Adding Emergency Department Data as a Measure of Crack Intensity}

The Drug Abuse Warning Network (DAWN) monitors drug-related visits to hospital emergency departments. Participating hospitals are non-federal, short-stay general surgical and medical hospitals with 24-hour emergency departments. It was established in the early 1970s, and has been managed by the Substance Abuse and Mental Health Services Administration in the early 1980s. Medical records are reviewed for mentions of alcohol and drugs, and data are extracted from those records and published in annual reports. While there are some concerns about how accurately DAWN measures local level of cocaine-related emergency department contacts, Caulkins (2001) demonstrates there is a strong relationship between cocaine prices obtained from law enforcement agencies and DAWN emergency department mentions for cocaine.

We obtained and digitized the annual reports from DAWN covering 1978 to 1999. The information reported varies from year to year. There is a breakdown by the type of the cocaine up to 1988 , but the form of drug is not reported after that so we use all cocaine mentions to calculate a per capita measure. This is a reasonable assumption given the large change in cocaine episodes during after the introduction of crack cocaine in the early 1980s. The national DAWN estimate of 4,777 episodes in 1981 increased to 168,751 episodes by 1999.

There are 27 cities that appear in the DAWN sample in at least some years. One of these was added to the DAWN sample in 1984, and six cities we removed in 1988. This leaves 20 cities, which are among the largest in the United States: Atlanta, Baltimore, Boston, Buffalo, Chicago, Dallas, Denver, Detroit, Los Angeles, Miami, Minneapolis, New Orleans, Newark NJ, Philadelphia, Phoenix, San Diego, San Francisco, and Washington DC.

Since 1991 the annual DAWN reports contain per-capita estimates of cocaine episodes for a given city. Episode numbers are provided in earlier years, together with the number of potential and actual hospitals participating in the survey. We use this information to scale per capita estimates as (episodes x potential hospitals) / (city population x participating hospitals). City population reported in DAWN does not always match the MSA population numbers in the Census data, because the participating counties differ from those in the MSA areas. To address this concern, population for the earlier years is scaled using the average differences between Census-based numbers and DAWN 
report numbers from 1991 to 1993. The necessary information was missing in 1978 in San Francisco, 1978 and 1979 in Baltimore and St. Louis, and 1978 to 1980 in Chicago, Los Angeles and New York.

We use DAWN data to estimate regression models that are similar to those presented in Table 7. In the original model, we regress high school graduation rates on the average murder rates during high school, cohort fixed effects, and sex- and race-specific geographic area effects. The first column of Table A5 contains results from this regression for the DAWN sample, which is 20 MSAs for the between 1980 and 1999. The coefficient on sex- and race-specific murder rates is negative and of similar in magnitude to those of the two MSA samples presented in Table 7. With a smaller sample, the coefficient is now statistically significant at the 10 percent level. Column (2) of Table A5 shows results when the murder rate coefficient is replaced with a variable measuring the rate of cocaine emergency room episodes when an individual is aged 16 to 18 years, which is the same period used to construct the murder rate variable. There is a negative relationship between high school graduation and this measure of crack market size, although the t-statistic is 1.1. Putting both the murder and cocaine episode rates together leaves the murder rate coefficient unchanged and still statistically significant at the 10 percent level, while the coefficient on cocaine episodes is around 10 percent smaller.

Columns (4) to (6) show the same three sets of results when the sample is restricted to males. The murder rate coefficient is again similar to that for the MSA samples in Table 7 and unchanged by the inclusion of cocaine episodes in column (6). This coefficient now has a t-statistic of being different than zero that is equal to 1.9. While the coefficient on the cocaine episode variable is negative and statistically significant at the ten percent level without the inclusion of murder rates in column (5), the t-statistic decreases to 1.5 with the inclusion of murder rates.

The results suggest that the estimated relationship between high school graduation and the murder rates experienced during high school are largely unaffected by adding the available DAWN data. While a negative relationship between high school graduation and market intensity cannot be established when using cocaine emergency room visits, this may be due to sample size and relative coarseness of the measure. 


\section{References}

Adler, William M. 1995. Land of Opportunity: One Family's Quest for the American Dream in the Age of Crack. New York: Atlantic Monthly Press.

Agar, Michael. 2003. "The Story of Crack: Towards a Theory of Illicit Drug Trends.” Addiction Research and Theory 11 (1): 3-29.

Caulkins, Jonathan P. 2001. "Drug Prices and Emergency Department Mentions for Cocaine and Heroin." American Journal of Public Health, 91(9): 1446-1448.

Cooper, Edith Fairman. 1998. "The Emergence of Crack Cocaine Abuse in the United States: A Public Health Perspective." CRS Report for Congress 1-78.

Copemann, Chester D., and Paula L. Shaw. 1975. "Selected demographic characteristics and patterns of drug abuse among treated addicts from a suburban community." British Journal of Addiction to Alcohol \& Other Drugs 70(2): 205-12.

Corcoran, Sean, and William N. Evans. 2010. "Income Inequality, the Median Voter, and the Support for Public Education.” NBER Working Paper No. 16097.

Grogger, Jeff, and Michael Willis. 2000. "The Emergence of Crack Cocaine and the Rise in Urban Crime Rates." The Review of Economics and Statistics, 82(4): 519-29.

Johnson, Bruce D., Andrew Golub and Jeffrey Fagan. 1995. "Careers in Crack, Drug Use, Drug Distribution, and Nondrug Criminality." Crime \& Delinquency, 41(3): 275-295. 
Table A1 Year Crack Arrives in 57 Largest Metropolitan Statistical Areas, Various Measures

\begin{tabular}{|c|c|c|c|c|c|}
\hline \multirow{3}{*}{ Metropolitan Statistical Area, State, Area Type } & \multicolumn{3}{|c|}{ Cocaine-related deaths } & \multicolumn{2}{|c|}{ Grogger \& Willis } \\
\hline & $\begin{array}{l}2 \text { years } \\
\text { in row }\end{array}$ & $\begin{array}{l}2 \text { of } 3 \\
\text { years }\end{array}$ & $\begin{array}{l}3 \text { years } \\
\text { in row }\end{array}$ & $\begin{array}{l}\text { Police } \\
\text { chiefs }\end{array}$ & $\begin{array}{l}\text { DAWN } \\
\text { increase }\end{array}$ \\
\hline & (1) & $(2)$ & (3) & (4) & (5) \\
\hline Albany-Schenectady-Troy, NY, MSA & 1985 & 1985 & 1994 & N.A. & N.A. \\
\hline Atlanta, GA, MSA & 1983 & 1983 & 1983 & 1981 & 1984 \\
\hline Baltimore, MD, PMSA & 1989 & 1985 & 1989 & 1988 & 1986 \\
\hline Bergen-Passaic, NJ, PMSA & 1991 & 1991 & 1991 & N.A. & N.A. \\
\hline Birmingham, AL, MSA & 1989 & 1989 & 1989 & N.A. & N.A. \\
\hline $\begin{array}{l}\text { Boston-Worcester-Lawrence-Lowell-Brockton, MA, } \\
\text { NECMA }\end{array}$ & 1986 & 1984 & 1986 & N.A. & 1986 \\
\hline Buffalo-Niagara Falls, NY, MSA & 1988 & 1988 & 1988 & 1986 & 1987 \\
\hline Charlotte-Gastonia-Rock Hill, NC-SC, MSA & 1989 & 1987 & 1989 & N.A. & N.A. \\
\hline Chicago, IL, PMSA & 1986 & 1986 & 1986 & 1988 & 1984 \\
\hline Cincinnati, OH-KY-IN, PMSA & 1987 & 1987 & 1990 & 1988 & N.A. \\
\hline Cleveland-Lorain-Elyria, OH, PMSA & 1986 & 1986 & 1986 & 1988 & 1983 \\
\hline Columbus, $\mathrm{OH}, \mathrm{MSA}$ & 1992 & 1992 & 1992 & 1986 & N.A. \\
\hline Dallas-Fort Worth-Arlington, TX, PMSA & 1985 & 1983 & 1985 & 1986 & 1987 \\
\hline Dayton-Springfield, OH, MSA & 1991 & 1989 & 1991 & N.A. & N.A. \\
\hline Denver, CO, PMSA & 1988 & 1988 & 1988 & 1986 & 1986 \\
\hline Detroit, MI, PMSA & 1985 & 1985 & 1985 & 1986 & 1984 \\
\hline Fort Lauderdale, FL, PMSA & 1984 & 1984 & 1984 & N.A. & N.A. \\
\hline Grand Rapids-Muskegon-Holland, MI, MSA & 1989 & 1989 & 1992 & N.A. & N.A. \\
\hline Greensboro-Winston-Salem-High Point, NC, MSA & 1987 & 1987 & 1987 & N.A. & N.A. \\
\hline Hartford, CT, NECMA & 1988 & 1988 & 1988 & N.A. & N.A. \\
\hline Houston, TX, PMSA & 1988 & 1988 & 1988 & N.A. & N.A. \\
\hline Indianapolis, IN, MSA & 1986 & 1986 & 1986 & 1988 & 1986 \\
\hline Kansas City, MO-KS, MSA & 1985 & 1985 & 1988 & 1982 & 1983 \\
\hline Los Angeles-Long Beach, CA, PMSA & 1982 & 1982 & 1985 & 1984 & 1984 \\
\hline Louisville, KY-IN, MSA & 1988 & 1988 & Never & N.A. & N.A. \\
\hline Memphis, TN-AR-MS, MSA & 1986 & 1986 & 1986 & N.A. & N.A. \\
\hline Miami, FL, PMSA & 1982 & 1980 & 1982 & N.A. & 1984 \\
\hline Middlesex-Somerset-Hunterdon, NJ, PMSA & 1991 & 1989 & 1991 & N.A. & N.A. \\
\hline Milwaukee-Waukesha, WI, PMSA & 1987 & 1987 & 1987 & 1991 & N.A. \\
\hline Minneapolis-St. Paul, MN-WI, MSA & 1986 & 1986 & 1986 & N.A. & N.A. \\
\hline Monmouth-Ocean, NJ, PMSA & 1986 & 1986 & 1986 & N.A. & N.A. \\
\hline Nashville, TN, MSA & 1988 & 1988 & 1988 & N.A. & N.A. \\
\hline $\begin{array}{l}\text { New Haven-Bridgeport-Stamford-Danbury-Water, CT, } \\
\text { NECMA }\end{array}$ & 1986 & 1984 & 1986 & N.A. & N.A. \\
\hline New Orleans, LA, MSA & 1986 & 1986 & 1986 & 1986 & 1987 \\
\hline New York, NY, PMSA & 1982 & 1982 & 1982 & 1985 & 1986 \\
\hline Newark, NJ, PMSA & 1986 & 1986 & 1986 & 1985 & 1985 \\
\hline Norfolk-Virginia Beach-Newport News, VA-NC, MSA & 1987 & 1987 & 1987 & 1988 & 1985 \\
\hline Oklahoma City, OK, MSA & 1988 & 1988 & 1991 & N.A. & N.A. \\
\hline Orange County, CA, PMSA & 1986 & 1986 & 1991 & N.A. & N.A. \\
\hline Orlando, FL, MSA & 1988 & 1988 & 1988 & N.A. & N.A. \\
\hline Philadelphia, PA-NJ, PMSA & 1985 & 1985 & 1985 & 1985 & 1985 \\
\hline Phoenix-Mesa, AZ, MSA & 1988 & 1988 & 1988 & N.A. & N.A. \\
\hline
\end{tabular}




\begin{tabular}{|c|c|c|c|c|c|}
\hline \multirow[b]{2}{*}{ Metropolitan Statistical Area, State, Area Type } & \multicolumn{3}{|c|}{ Cocaine-related deaths } & \multicolumn{2}{|c|}{ Grogger \& Willis } \\
\hline & $\begin{array}{c}2 \text { years } \\
\text { in row } \\
(1)\end{array}$ & $\begin{array}{c}2 \text { of } 3 \\
\text { years } \\
(2)\end{array}$ & $\begin{array}{c}3 \text { years } \\
\text { in row } \\
\text { (3) }\end{array}$ & $\begin{array}{l}\text { Police } \\
\text { chiefs } \\
\text { (4) }\end{array}$ & $\begin{array}{c}\text { DAWN } \\
\text { increase } \\
(5)\end{array}$ \\
\hline Pittsburgh, PA, MSA & 1988 & 1988 & 1988 & 1987 & N.A. \\
\hline Portland-Vancouver, OR-WA, PMSA & 1988 & 1988 & 1988 & N.A. & N.A. \\
\hline Providence-Warwick-Pawtucket, RI, NECMA & 1987 & 1987 & 1987 & N.A. & N.A. \\
\hline Riverside-San Bernardino, CA, PMSA & 1983 & 1983 & 1987 & N.A. & N.A. \\
\hline Rochester, NY, MSA & 1988 & 1986 & 1988 & N.A. & N.A. \\
\hline Sacramento, CA, PMSA & 1986 & 1981 & 1986 & N.A. & N.A. \\
\hline St. Louis, MO-IL, MSA & 1989 & 1989 & 1989 & 1986 & 1987 \\
\hline Salt Lake City-Ogden, UT, MSA & 1988 & 1986 & 1991 & N.A. & N.A. \\
\hline San Antonio, TX, MSA & 1994 & 1992 & 1994 & N.A. & N.A. \\
\hline San Diego, CA, MSA & 1988 & 1986 & 1988 & 1984 & 1984 \\
\hline San Francisco-Oakland, CA, PMSA & 1983 & 1983 & 1986 & 1985 & 1985 \\
\hline San Jose, CA, PMSA & 1984 & 1984 & 1984 & N.A. & N.A. \\
\hline Seattle-Bellevue-Everett, WA, PMSA & 1984 & 1984 & 1989 & N.A. & N.A. \\
\hline Tampa-St. Petersburg-Clearwater,FL, MSA & 1984 & 1984 & 1987 & 1985 & N.A. \\
\hline Washington, DC-MD-VA-WV, PMSA & 1985 & 1985 & 1985 & 1986 & 1986 \\
\hline Correlation with Column (1) Dates & -- & 0.90 & 0.75 & 0.43 & 0.37 \\
\hline
\end{tabular}

The Nassua/Suffolk MSA is omitted because cocaine-related deaths were already present in consecutive years prior to 1981. One MSA never had cocaine-related deaths for three years in a row. The abbreviations at the end of each location are: MSA for Metropolitan Statistical Area, PMSA for Primary Metropolitan Statistical Area, and NECMA for New England County Metropolitan Area. 
Table A2 Year Crack Arrives in 40 States and DC, Various Measures

\begin{tabular}{|c|c|c|c|}
\hline \multirow[t]{2}{*}{ State } & 2 years in row & 2 of 3 years & 3 years in row \\
\hline & (1) & (2) & (3) \\
\hline Alabama & 1986 & 1984 & 1986 \\
\hline Arizona & 1983 & 1983 & 1983 \\
\hline Arkansas & 1987 & 1987 & 1987 \\
\hline California & 1981 & 1981 & 1981 \\
\hline Colorado & 1984 & 1984 & 1984 \\
\hline Connecticut & 1986 & 1984 & 1986 \\
\hline Delaware & 1988 & 1988 & 1988 \\
\hline District of Columbia & 1985 & 1985 & 1985 \\
\hline Florida & 1982 & 1980 & 1982 \\
\hline Georgia & 1983 & 1983 & 1983 \\
\hline Illinois & 1985 & 1985 & 1985 \\
\hline Indiana & 1985 & 1983 & 1985 \\
\hline Iowa & 1988 & 1988 & 1988 \\
\hline Kansas & 1986 & 1986 & 1986 \\
\hline Kentucky & 1987 & 1987 & 1987 \\
\hline Louisiana & 1986 & 1986 & 1986 \\
\hline Maryland & 1985 & 1985 & 1985 \\
\hline Massachusetts & 1986 & 1984 & 1986 \\
\hline Michigan & 1984 & 1984 & 1984 \\
\hline Minnesota & 1986 & 1980 & 1986 \\
\hline Mississippi & 1986 & 1986 & 1986 \\
\hline Missouri & 1984 & 1984 & 1984 \\
\hline Nebraska & 1987 & 1985 & 1987 \\
\hline Nevada & 1987 & 1987 & 1987 \\
\hline New Jersey & 1986 & 1984 & 1986 \\
\hline New Mexico & 1985 & 1985 & 1985 \\
\hline New York & 1982 & 1982 & 1982 \\
\hline North Carolina & 1987 & 1985 & 1987 \\
\hline Ohio & 1986 & 1986 & 1986 \\
\hline Oklahoma & 1988 & 1988 & 1991 \\
\hline Oregon & 1987 & 1985 & 1987 \\
\hline Pennsylvania & 1985 & 1985 & 1985 \\
\hline Rhode Island & 1987 & 1987 & 1987 \\
\hline South Carolina & 1985 & 1985 & 1985 \\
\hline Tennessee & 1986 & 1986 & 1986 \\
\hline Texas & 1985 & 1985 & 1985 \\
\hline Utah & 1988 & 1986 & 1991 \\
\hline Virginia & 1984 & 1984 & 1984 \\
\hline Washington & 1984 & 1984 & 1984 \\
\hline West Virginia & 1987 & 1985 & 1987 \\
\hline Wisconsin & 1987 & 1987 & 1987 \\
\hline Correlation with Column (1) & -- & 0.78 & 0.95 \\
\hline
\end{tabular}

Ten states with small black populations are omitted (HI, AK, ID, ME, MT, NH, ND, SD, VT, WY). The criterion for the three most populous states (CA, NY, and TX) is two or more deaths in two consecutive years. 
Table A3 Linear Probability Estimates of High School Graduation Models, Cohorts that Turned 18 1976-1999, Current State of Residence

\begin{tabular}{|c|c|c|c|c|c|c|}
\hline & \multicolumn{3}{|c|}{ Males } & \multicolumn{3}{|c|}{ Females } \\
\hline & $\begin{array}{c}\text { Full } \\
\text { sample, } \\
\text { 1976-99 } \\
(1) \\
\end{array}$ & $\begin{array}{c}\text { Restricted } \\
\text { sample, } \\
1978-1999 \\
(2) \\
\end{array}$ & $\begin{array}{c}\text { Restricted, } \\
\text { 1978-99, } \\
+ \text { Covariates } \\
(3) \\
\end{array}$ & $\begin{array}{c}\text { Full } \\
\text { sample, } \\
\text { 1976-99 } \\
(4) \\
\end{array}$ & $\begin{array}{c}\text { Restricted } \\
\text { sample, } \\
1978-1999 \\
(5) \\
\end{array}$ & $\begin{array}{c}\text { Restricted, } \\
\text { 1978-99, } \\
+ \text { Covariates } \\
(6)\end{array}$ \\
\hline PreCrackTrend $_{c g}$ & $\begin{array}{c}0.0035 * * * \\
(0.0007)\end{array}$ & $\begin{array}{c}0.0029 * * \\
(0.0009)\end{array}$ & $\begin{array}{l}0.0023^{* *} \\
(0.0009)\end{array}$ & $\begin{array}{c}0.0023 * * * \\
(0.0004)\end{array}$ & $\begin{array}{c}0.0027 * * * \\
(0.0006)\end{array}$ & $\begin{array}{c}0.0027 * * * \\
(0.0006)\end{array}$ \\
\hline YrsAfterCrack $_{c g}$ & $\begin{array}{c}-0.0034 * * * \\
(0.0007)\end{array}$ & $\begin{array}{c}-0.0030 * * * \\
(0.0007)\end{array}$ & $\begin{array}{c}-0.0026^{* * *} \\
(0.0007)\end{array}$ & $\begin{array}{l}-0.00003 \\
(0.00044)\end{array}$ & $\begin{array}{c}0.0001 \\
(0.0004)\end{array}$ & $\begin{array}{c}0.0002 \\
(0.0005)\end{array}$ \\
\hline Observations & $1,562,768$ & $1,143,620$ & 1.143 .620 & $1,617,620$ & $1,186,322$ & $1,186,322$ \\
\hline
\end{tabular}

Standard errors allow for arbitrary correlation in errors within state. All models include cohort and geographic fixed effects plus a dummy variable for race. Covariate models include the percentage of employment in manufacturing; the percentage of moms that are high school dropouts, high school graduates, or have some college education; the percentage of children under age 17 without a father present; the log of family income; the average expenditures per representative black student; the average percentage of the representative black student's school that is black; the racial fractionalization of the school a representative black student attends; the family income Gini coefficient for the school a representative black student attends, and the unemployment rate for individuals with less than a college degree. 
Table A4 Estimates of the Impact of Crack Intensity on the High School Graduation Rates of Black Males, Based on the Separate Impacts of Murder and Prison, Including a Sample of Consistent States

\begin{tabular}{|c|c|c|c|}
\hline In sample: & (1) & $(2)$ & (3) \\
\hline & \multicolumn{3}{|c|}{ Sample from Table 7: All States With Any Prison Data } \\
\hline $\begin{array}{l}\text { Race specific murder rate during HS } \\
\text { (x 1000) }\end{array}$ & & $\begin{array}{c}-0.237 * * \\
(0.077) \\
{[0.024]}\end{array}$ & $\begin{array}{c}-0.130 * * \\
(0.061) \\
{[0.013]}\end{array}$ \\
\hline Race Specific Prison Intake Rate & $\begin{array}{c}-0.961 * * * \\
(0.247) \\
{[-0.028]}\end{array}$ & & $\begin{array}{c}-0.721 * * \\
(0.251) \\
{[-0.021]}\end{array}$ \\
\hline $\begin{array}{l}\mathrm{R}^{2} \\
\text { Observations }\end{array}$ & $\begin{array}{c}0.027 \\
971,749\end{array}$ & $\begin{array}{c}0.026 \\
971,749\end{array}$ & $\begin{array}{c}0.027 \\
971,749\end{array}$ \\
\hline $\begin{array}{l}\text { Race specific murder rate during HS } \\
\text { (x 1000) }\end{array}$ & Additional Sampl & $\begin{array}{c}\text { with Prisc } \\
-0.385^{* * *} \\
(0.071) \\
{[-0.039]}\end{array}$ & $\begin{array}{c}\text { r Every Year } \\
-0.193^{* *} \\
(0.057) \\
{[0.020]}\end{array}$ \\
\hline Race Specific Prison Intake Rate & $\begin{array}{c}-1.497 * * * \\
(0.262) \\
{[-0.043]}\end{array}$ & & $\begin{array}{c}-1.020 * * \\
(0.263) \\
{[-0.030]}\end{array}$ \\
\hline $\begin{array}{l}\mathrm{R}^{2} \\
\text { Observations }\end{array}$ & $\begin{array}{c}0.024 \\
453,111 \\
\end{array}$ & $\begin{array}{c}0.024 \\
453,111 \\
\end{array}$ & $\begin{array}{c}0.024 \\
453,111 \\
\end{array}$ \\
\hline
\end{tabular}

$* \mathrm{p}<0.10, * * \mathrm{p}<0.05, * * * \mathrm{p}<0.01$

Standard errors are in parentheses, and allow for arbitrary correlation in errors within a state. The square brackets contain the estimated effect of the change in the black murder rate on graduation rates (e.g., the value of 0.005 in the top panel of the first column represents a 2.7 percent decrease in graduation rates). Each model contains fixed effects for a full set of State x sex x race interactions, and for cohort.

Table A5 OLS Estimates of the Impact of Homicide Rates and Emergency Room Mentions on High School Graduation, Current MSA Residents, Cohorts that Turned 18 over 1983-1999

\begin{tabular}{lcccccc}
\hline \hline & \multicolumn{3}{c}{ Both Sexes } & \multicolumn{3}{c}{ Males } \\
\cline { 2 - 6 } & $(1)$ & $(2)$ & $(3)$ & $(4)$ & $(5)$ & $(6)$ \\
\hline Sex/race specific murder rates of & $-0.1105^{*}$ & & $-0.1084^{*}$ & $-0.1352^{*}$ & & $-0.1316^{*}$ \\
20-24 year olds during HS (x 1000) & $(0.0614)$ & & $(0.0610)$ & $(0.0685)$ & & $(0.0678)$ \\
& & & & & & \\
Cocaine ER rates & & -0.0338 & -0.0299 & & $-0.0565^{*}$ & -0.0479 \\
during HS (x 1000) & & $(0.0306)$ & $(0.0316)$ & & $(0.0308)$ & $(0.0327)$ \\
$\mathrm{R}^{2}$ & & & & & & \\
Observations & 0.029 & 0.029 & 0.028 & 0.032 & 0.032 & 0.032 \\
\hline \hline
\end{tabular}

* $\mathrm{p}<0.10, * * \mathrm{p}<0.05, * * * \mathrm{p}<0.01$

Standard errors are in parentheses, and allow for arbitrary correlation in errors within a geographic area (state or MSA). Each model contains fixed effects for a full set of State $\mathrm{x}$ sex $\mathrm{x}$ race interactions, and for cohort. 